\title{
Multiple evanescent white dot syndrome (MEWDS): update on practical appraisal, diagnosis and clinicopathology; a review and an alternative comprehensive perspective
}

Ioannis Papasavvas ${ }^{1 *}$ (D), Alessandro Mantovani ${ }^{2}$, Ilknur Tugal-Tutkun ${ }^{3}$ and Carl P. Herbort Jr ${ }^{1 *}$

\begin{abstract}
Background: Multiple evanescent white dot syndrome (MEWDS) is a rare inflammatory eye condition affecting the outer retina as a consequence of choriocapillaris non perfusion. The pathophysiology of MEWDS will be discussed based clinical appraisal and on multimodal imaging appraisal.

Methods: Narrative review and perspective opinion.

Results: Literature review results helped us to put forward (1) the specific symptomatology (decreased/blurred vision, photopsia, subjective scotomas), (2) the ill-asserted character of clinical findings (foveal granularity, white dots in fundoscopy), (3) and the crucial importance of multimodal imaging with the diagnostic triad of ICGA hypofluorescent areas, BL-FAF hyperautofluorescent areas and loss/damage of IS/OS-ellipsoid zone on SD-OCT that characterise the disease and can practically help the clinician to diagnose MEWDS. A comprehensive alternative perspective of the disease was formulated.

Conclusions: The bulk of evidence that we are presenting in this review, thanks to new performing non-invasive and invasive imaging modalities, is sufficiently compelling to consider MEWDS as a primary choriocapillaritis/ inflammatory choriocapillaropathy. Multimodal imaging allows the clinician to diagnose MEWDS with a high level of certainty and ensures a precise follow-up.
\end{abstract}

Keywords: MEWDS, ICGA, PICCPS, BL-FAF

\section{Introduction}

Multiple evanescent white dot syndrome (MEWDS) is a rare posterior uveitis, characterised by numerous pale whitish dots seen in the posterior pole and the midperiphery [1]. As its name indicates the appearance of the dots is limited in time and may not be present when the patient consults. In the post-acute phase, a granular

\footnotetext{
*Correspondence: i.s.papasavvas@gmail.com; cph@herbortuveitis.ch 'Retinal and Inflammatory Eye Diseases, Centre for Ophthalmic Specialized Care (COS), Clinic Montchoisi Teaching Centre, Rue Charles-Monnard 6, $\mathrm{CH}-1003$ Lausanne, Switzerland

Full list of author information is available at the end of the article
}

aspect of the fovea persists [2]. Patients complain of subjective scotomas and photopsia. In some cases, up to $50 \%$, the ocular disease is preceded by a flu-like viral episode [1]. Except rare reported bilateral forms, it is a unilateral disease and affects young to middle-aged adults, being predominant in women and in myopic patients [3]. It is best diagnosed by indocyanine green angiography (ICGA) identifying scattered areas of hypofluorescence [4-6] or by blue-light fundus autofluorescence (BL-FAF) showing scattered hyper-autofluorescent areas co-localising with the ICGA hypofluorescent areas [7].

\section{Springer Open}

(0) The Author(s). 2021 Open Access This article is licensed under a Creative Commons Attribution 4.0 International License, which permits use, sharing, adaptation, distribution and reproduction in any medium or format, as long as you give appropriate credit to the original author(s) and the source, provide a link to the Creative Commons licence, and indicate if changes were made. The images or other third party material in this article are included in the article's Creative Commons licence, unless indicated otherwise in a credit line to the material. If material is not included in the article's Creative Commons licence and your intended use is not permitted by statutory regulation or exceeds the permitted use, you will need to obtain permission directly from the copyright holder. To view a copy of this licence, visit http://creativecommons.org/licenses/by/4.0/. 
Spectral domain optical coherence tomography (SDOCT) shows damage to the outer segments of the photoreceptor line [8]. Visual loss can be minor to very pronounced, depending on the areas involved and the severity of the process [9]. Visual field testing can show faint to pronounced scotomas with an often enlarged blind spot [10, 11]. Visual function is restored without treatment within 8-10 weeks and the disease does usually not recur. If there is a recurrence, idiopathic multifocal choroiditis has to be suspected, as these two diseases can overlap [12]. MEWDS is considered to be on the benign end of the primary choriocapillaritis entities, as it is usually reversible without treatment [13].

\section{Historical aspects and nomenclature}

Between the late 1960s and the early 1990s, many chorioretinal diseases were described and characterised, starting with acute posterior multifocal placoid pigment epitheliopathy (APMPPE) reported by Gass in 196 8[14]. Multifocal choroiditis, now called idiopathic multifocal choroiditis (MFC) was reported in 1969 by Krill [15] and in 1973 by Dorsh and Nozik [16]. In 1980 birdshot retinochoroiditis was described [17], in 1990 acute syphilitic posterior placoid chorioretinitis (ASPPC) [18] and in 1992 acute zonal occult outer retinopathy (AZOOR) [19] to cite only the more important entities and leaving out the many more sub-entities. The descriptions of these conditions were very accurate, based on precise phenomenological observation of signs and precise follow-up. However, in the absence of multimodal imaging, the pathophysiological explanations were often conjectural and left the clinicians doubtful and uncomfortable about disease mechanisms. An example of such an erroneous interpretation is APMPPE, a disease attributed to the retinal pigment epithelium (RPE) by Gass and correctly interpreted as a choriocapillaritis by Deutman in 1972 who called the disease acute multifocal ischaemic choriocapillaritis (AMIC) [20]. Therefore, when in 1995 an article proposed to assemble these diseases within the group of the "white dot syndromes" (WDS), this terminology was quickly adopted by the ophthalmological community at large [21]. Today we know that disease mechanisms in this group differ substantially and there is no reason to use this potpourri classification any longer.

MEWDS was part of these newly described entities during the glorious late 1960s to the early 1990s. In 1984, Lee Jampol, Paul Sieving and colleagues published two remarkable articles precisely describing the clinical and electrophysiological characteristics of the disease $[22,23]$. The authors did not venture to give a pathophysiological hypothesis but gave a very comprehensive and detailed clinical description. Unfortunately, MEWD $\mathrm{S}$ was also included in the WDS group. With the availability of more performing imaging modalities such as ICGA and SD-OCT it was possible to demonstrate that the disease was caused by vaso-occlusive problems at the level of the inner choroid producing ischaemia in the outer retina and damage to the outer segments of the photoreceptors. By its disease mechanism, namely inflammatory choriocapillaris non-perfusion, MEWDS distinguishes itself from other diseases classified in the WDS group, such as birdshot chorioretinitis, characterised by choroidal stromal infiltration. The WDS terminology is therefore inappropriate, and these diseases should, more appropriately, be classified according to their disease mechanisms including choriocapillaritis, stromal choroiditis and other mechanisms [24].

In 1988, a group from San Francisco described an entity which they called "Acute idiopathic blind spot enlargement. A big blind spot syndrome without optic disc edema" (AIBSE) [25], later identified as an expression of MEWDS by the group of Donald Gass [26]. AIBSE could be linked to MEWDS by performing ICGAs in AIBSE patients without fundus white dots that showed hypofluorescent areas of choriocapillaris non-perfusion typical of MEWDS [27]. In addition to AIBSE cases, many typical MEWDS cases showed an enlarged blind spot $[28,29]$.

More recently, despite the ICGA signs typical of MEWDS hypofluorescence indicating choriocapillaris non-perfusion, it was hypothesised that MEWDS was a primary photoreceptor disease, a conjecture hard to take as explained hereunder [30].

Classification criteria were presented recently by the SUN group. Unfortunately, similar to classification criteria of other posterior uveitis entities by the group, they are of limited use in practice, as they neither included ICGA nor BL-FAF in the proposed criteria [31].

\section{Clinical findings and disease course}

The typical patient with MEWDS is a myopic woman between the ages of 20 and 40 who presents with acutely diminished visual acuity, photopsias, and temporal visual field defects in one eye following an episode of flu-like symptoms. It is a rare disease accounting for $1.24 \%$ of uveitis diagnoses in our setting. Ocular examination typically reveals trace vitreous cells, numerous isolated or confluent yellow-white spots and dots ranging in size from $100 \mu \mathrm{m}$ to more than $200 \mu \mathrm{m}$, at the level of the RPE or deep retina, mostly concentrated in the paramacular and peripapillary area and randomly scattered in the mid-peripheral retina, foveal granularity, and mild optic disc inflammation in the involved eye. The natural evolution of typical MEWDS is characterized by spontaneous resolution of fundus findings and recovery of visual function within several weeks. The clinical 
diagnosis of MEWDS is confirmed by multimodal imaging at presentation and during follow-up.

Table 1 shows demographic and clinical data from the original description of 11 MEWDS cases by Jampol et al. [22] and data from 3 large series published in the last decade [3, 32, 33]. In contrast to the original description of unilateral monophasic nature of MEWDS, recent large cohorts have shown simultaneous or sequential involvement of both eyes in up to $10 \%$ of patients and recurrences in up to $14 \%[3,32,33]$. Mild involvement of the other eye could be detected by ICGA or OCT imaging [3]. Foveal granularity was documented in 70-94\% of cases, consistent with the original description; on the other hand, a diagnosis of MEWDS could still be made in the absence of characteristic white dots in recent cohorts $[3,33]$. In fact, foveal granularity can be the presenting finding in patients who have suggestive symptoms of MEWDS but do not have white dots on fundus examination $[2,34]$. The clinician can see patients with a normal fundus despite the very recent onset of symptoms. Because of the transient nature of white dots, a characteristic finding is a yellowish macula with granularity which can last longer and could be the only finding seen by the ophthalmologist at the time of examination in the post-acute phase. An incomplete visual recovery is another atypical feature in MEWDS patients.

Although MEWDS could be considered a "common cold" of the retina because of the transient nature of morphologic and functional changes, [35] Bosello et al. [32] have reported recovery of visual acuity to 0.0 LogMAR or better in $80 \%$ of MEWDS patients; and they found that poor initial visual acuity and young age were associated with incomplete visual recovery. Even though foveal granularity persisted at 3 months in $40 \%$ of their patients, it did not seem to be associated with poor recovery of visual function [32]. However, hyperfluorescent disc on fluorescein angiography (FA) at presentation was more frequent in patients with incomplete visual recovery (75\% versus 42\%) [32]. Patients who developed choroidal neovessels (CNVs) as a cause of poor visual outcome had been already excluded from their analysis [32]. Marsiglia et al. [3] have reported persistent peripapillary atrophy (23.5\%) and multifocal pigmentary changes (5.8\%) as sequelae of MEWDS in 34 patients who had presented with a typical episode and showed a mean recovery of visual acuity from 0.41 LogMAR to 0.03 LogMAR. Hamed et al. [10] were the first to show that the enlargement of the blind spot may persist for several months after the resolution of fundus lesions and recovery of visual acuity in some MEWDS patients.

Focal choroidal excavation and macular or peripapillary CNVs are rare complications of MEWDS and may appear several months or years after the resolution of white dots [36-40]. There are also reports of patients who present concurrently with CNVs and MEWDS or develop characteristic MEWDS lesions later during follow-up [41-44]. In such cases, CNVs may be an inaugural sign of MEWDS or a trigger of the MEWDS phenotype [42-44].

\section{Visual field testing and imaging investigation of MEWDS}

Visual field testing

Reports on isolated MEWDS cases usually signal visual field impairment but reports of larger series with specific analysis of visual field changes are scarce [45]. Visual field testing and microperimetry show that functional consequences can be quite diverse, going from large central scotomas to absence of visual field impairment. In our series of 20 patients, mean MD (mean defect) amounted to $6.1 \pm 2.8$ (normal <2) with values from 0.3 to 21.2. Microperimetry was more appropriate in determining reduction of function. In our experience, 8 out of 9 tested patients had a significantly decreased microperimetry score in the MEWDS eye compared to the contralateral normal eye $(357 \pm 106.7$ versus $465.3 \pm 47.8) \quad(p<0.016$, Student's t-test) (Fig. 1). Obviously the extent of visual field damage depends on the severity of the MEWDS episode that can reach from subtle to very pronounced, which is the case for all choriocapillaritis entities that can have different grades of involvement depending on the importance of the choriocapillaris/ choroidal vaso-occlusive process.

Table 1 Demographic and clinical data from MEWDS case series

\begin{tabular}{|c|c|c|c|c|c|c|c|c|c|c|c|}
\hline \multirow[t]{2}{*}{ Author/ year } & \multirow[t]{2}{*}{ No } & \multicolumn{8}{|c|}{ Demographic and clinical features at presentation } & \multicolumn{2}{|l|}{ Course } \\
\hline & & $\begin{array}{l}\text { Mean Age } \\
\text { (y) }\end{array}$ & $\begin{array}{l}\text { F gend } \\
\%\end{array}$ & $\begin{array}{l}\text { Preceding flulike illness } \\
\%\end{array}$ & $\begin{array}{l}\text { Myopia } \\
\%\end{array}$ & $\begin{array}{l}\text { UI } \\
\%\end{array}$ & $\begin{array}{l}\text { WD } \\
\%\end{array}$ & $\begin{array}{l}\text { Foveal granularity } \\
\%\end{array}$ & $\begin{array}{l}\text { OD infl } \\
\%\end{array}$ & $\begin{array}{l}\text { MT to recovery } \\
(w)\end{array}$ & $\begin{array}{l}\text { Recurrence } \\
\%\end{array}$ \\
\hline Jampol 1984 [22] & 11 & 28 & 90.9 & 45 & N/A & 100 & 100 & 90.9 & N/A & 7 & 0 \\
\hline Marsiglia 2016 [3] & 34 & 28.7 & 76.4 & 8.8 & 85.7 & 94.1 & 85.3 & 94.1 & 79.4 & 10 & 8.8 \\
\hline Bosello 2020 [32] & 51 & 29.6 & 80.4 & 23.5 & N/A & 90.2 & N/A & 70.3 & 16.2 & $\mathrm{~N} / \mathrm{A}$ & 11.7 \\
\hline Ramakri. 2021 [33] & 73 & 35.2 & 79.5 & 23 & 48 & 99 & 92 & 74 & 52 & $\mathrm{~N} / \mathrm{A}$ & 14 \\
\hline
\end{tabular}

No number of patients, UI unilateral involvement, $M T$ mean time.

$Y$ years, $W D$ white dots, $w$ weeks.

$F$ gend female gender, $O D$ infl Optic disc inflammation, N/A non applicable 


\section{Multimodal imaging}

Multimodal imaging has become the mainstay of diagnosis of MEWDS. In our diagnostic arsenal we have noninvasive methods (BL-FAF, SD-OCT, VF, OCT-A) and invasive methods (FA, ICGA) to detect pathological lesions in the retina and choroid.

FA, classically used in posterior uveitis has minimal valueadded potential in MEWDS. The first substantial progress in imaging MEWDS was achieved by ICGA in the mid-1990s. This was followed by BL-FAF clearly identifying the same MEWDS lesions as those seen by ICGA, but in a noninvasive fashion, and SD-OCT morphologically demonstrating loss or damage of the photoreceptor outer segments.

\section{Laser flare photometry/intraocular inflammation}

MEWDS is not associated with detectable anterior inflammation, even when laser flare photometry is used the sparse subclinical inflammation is low. In our setting, the mean level of flare in a series of 20 MEWDS patients amounted to $6.1 \pm 2.8$ (normal values $4-6 \mathrm{ph} /$ $\mathrm{ms}$ ) with $12.4 \mathrm{ph} / \mathrm{ms}$ being the highest value. In 6 of 20 patients slight posterior vitritis was noted.

\section{Fundus photography}

MEWDS fundus examination usually displays multiple, small whitish dots located around the optic disc or scattered throughout the posterior pole and the midperiphery. In addition to the multiple white lesions, another typical feature is the granular appearance of the fovea, which can be present even as a stand-alone feature (Fig. 2). Since the dots can disappear very rapidly, it is also possible that fundoscopy shows absence of pathology if the patient does not consult the clinician at an early stage [2] (Fig. 3). In our series white dots were recorded in only $6 / 20(33.3 \%)$ patients indicating that it is a good disease defining criterion when present that however has a limited sensitivity, probably because patients present late. However, granularity of the fovea was noticed in 13/20 (65\%) patients and represents a more reliable sign. Fundoscopic signs together with symptoms of photopsia and subjective scotomas are no more than diagnostic hints with diagnosis confirmed by the triad ICGA, BL-FAF and SD-OCT. Further fundoscopic signs can comprise images of $\mathrm{CNVs}$ and haemorrhages as shown on Fig. 4.

\section{Fluorescein angiography (FA)}

Fluorescein Angiography findings in MEWDS consist of hyperfluorescent patchy lesions that can be quasi absent or very minimal; these FA signs appear in the early phases but show themselves more clearly in the mid-to-

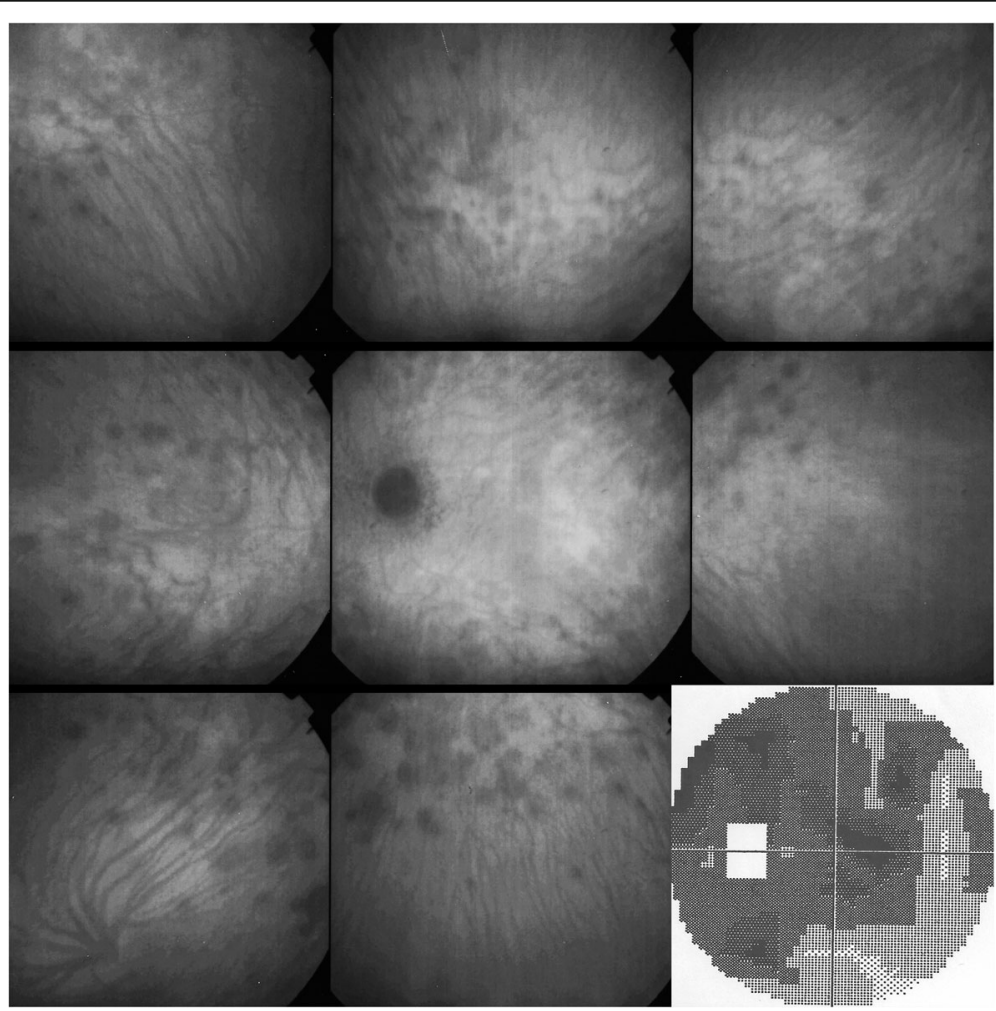

Fig. 1 MEWDS patient referred for suspected retrobulbar neuritis with severe visual field (VF) impairment. ICGA shows numerous hypofluorescent areas and a peripapillary hypofluorescent annulus explaining the severe VF deficit. VF returned to normal after 8 weeks 


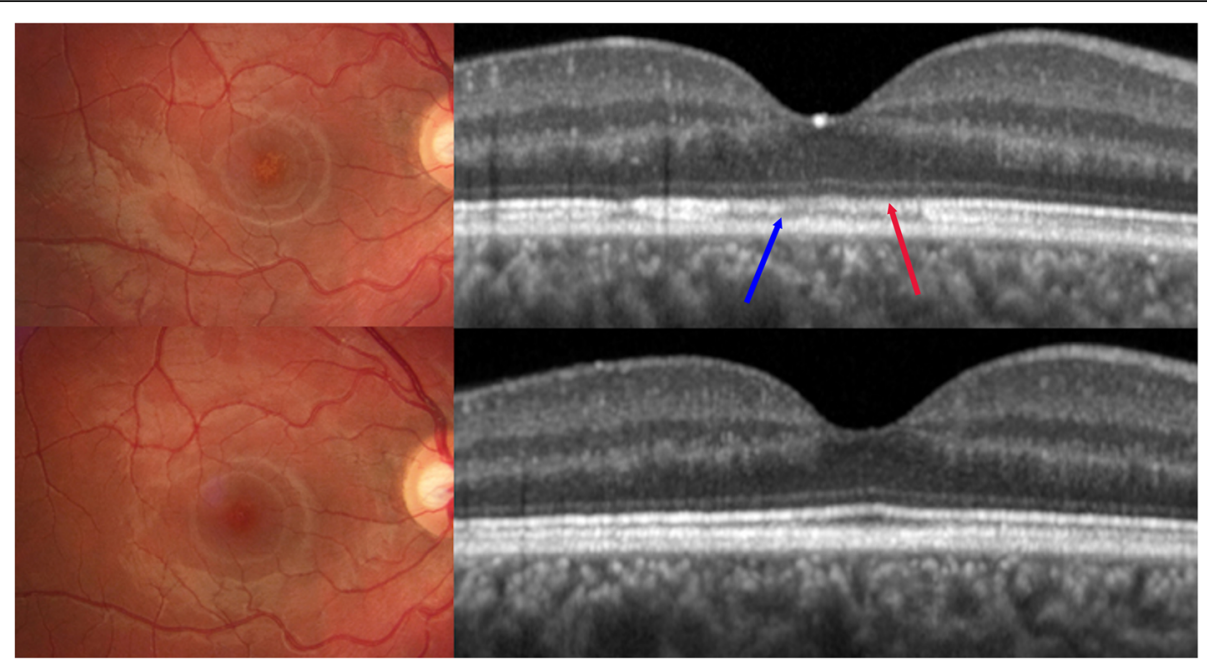

Fig. 2 Fundus / ICGA / BL-FAF signs in a typical MEWDS case. Faint fundal white dots are visible at presentation (top left), quickly disappearing on day 2 (D2) (middle left) and barely visible on day 3 (D3) (bottom left). BL-FAF hyperautofluorescence (top right) and ICGA hypofluorescence (bottom right) clearly identify the diseased areas

late phases of the angiography. They can also be very pronounced in some cases (Fig. 5).

The explanation for FA patchy hyperfluorescent areas is probably similar to what occurs in APMPPE or MFC where FA hyperfluorescence especially in the late phases can be pronounced in severe cases representing a reactive retinal vasodilatation and exudation secondary to outer retinal ischaemia caused by choriocapillaris hypo or non-perfusion [13, 46, 47]. Indeed, choroidal haemodynamic problems have been demonstrated in several studies [5, 6, 48-50]. Moreover, impaired choroidal perfusion was identified as a common denominator of choriocapillaritis entities including MEWDS [51]. As for APMPPE the degree of FA patchy hyperfluorescence depends on the severity of the vaso-occlusive process. Because of the discrete and sometimes absent FA signs, FA is of limited use in MEWDS. Additional signs found on
FA are disc hyperfluorescence as well as peripheral retinal vasculitis sometimes described [52] (Fig. 6).

\section{Indocyanine green angiography (ICGA)}

Very quickly after ICGA started to be available and used at large the crucial importance of this imaging modality became apparent for MEWDS [4]. ICGA findings consist of patchy hypofluorescent areas in the posterior pole and in the mid periphery as well as around the optic disc. ICGA hypofluorescence is especially well visible in the late angiographic phase, which is speaking more for choriocapillaris hypoperfusion than for total nonperfusion (Fig. 7). This could also explain the usually benign course of the disease.

The lesions exactly co-localise with BL-FAF hyperautofluorescent areas and correspond to photoreceptor outer segment loss or damage on SD-OCT (Fig.

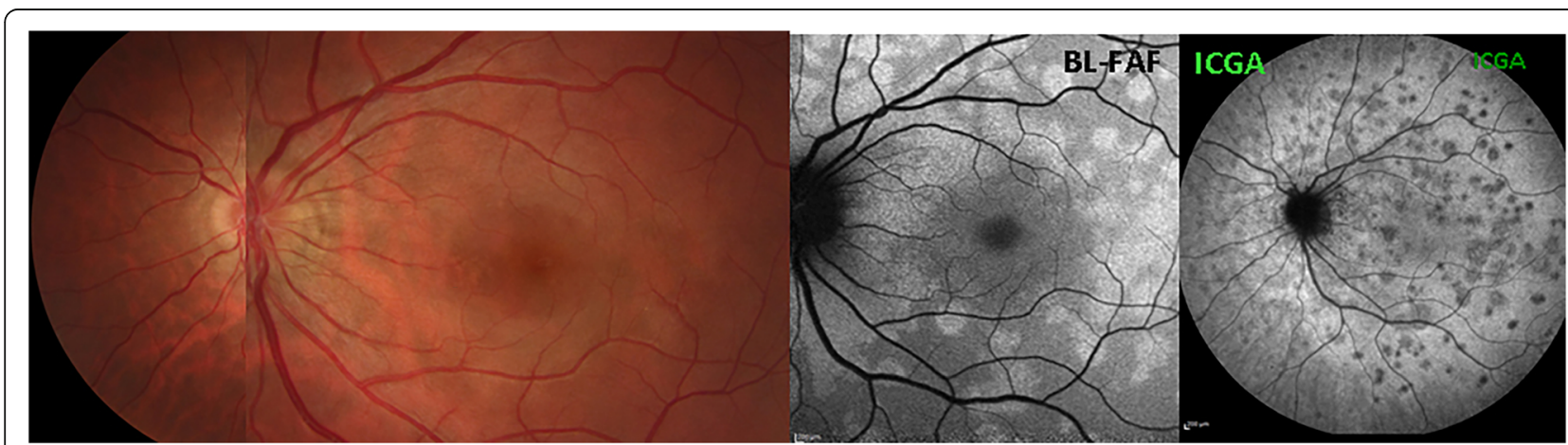

Fig. 3 Fundus images in MEWDS. Fundus, BL-FAF and ICGA in a MEWDS patient that consulted 3 days after symptoms of photopsias and subjective scotomas. Fundus showed absence of white dots and foveal granularity. BL-FAF (middle image) showed numerous prominent areas of hyperautofluorescence, while ICGA late phase frame revealed numerous dark dots co-localising with BL-FAF hyperautofluorescent areas 


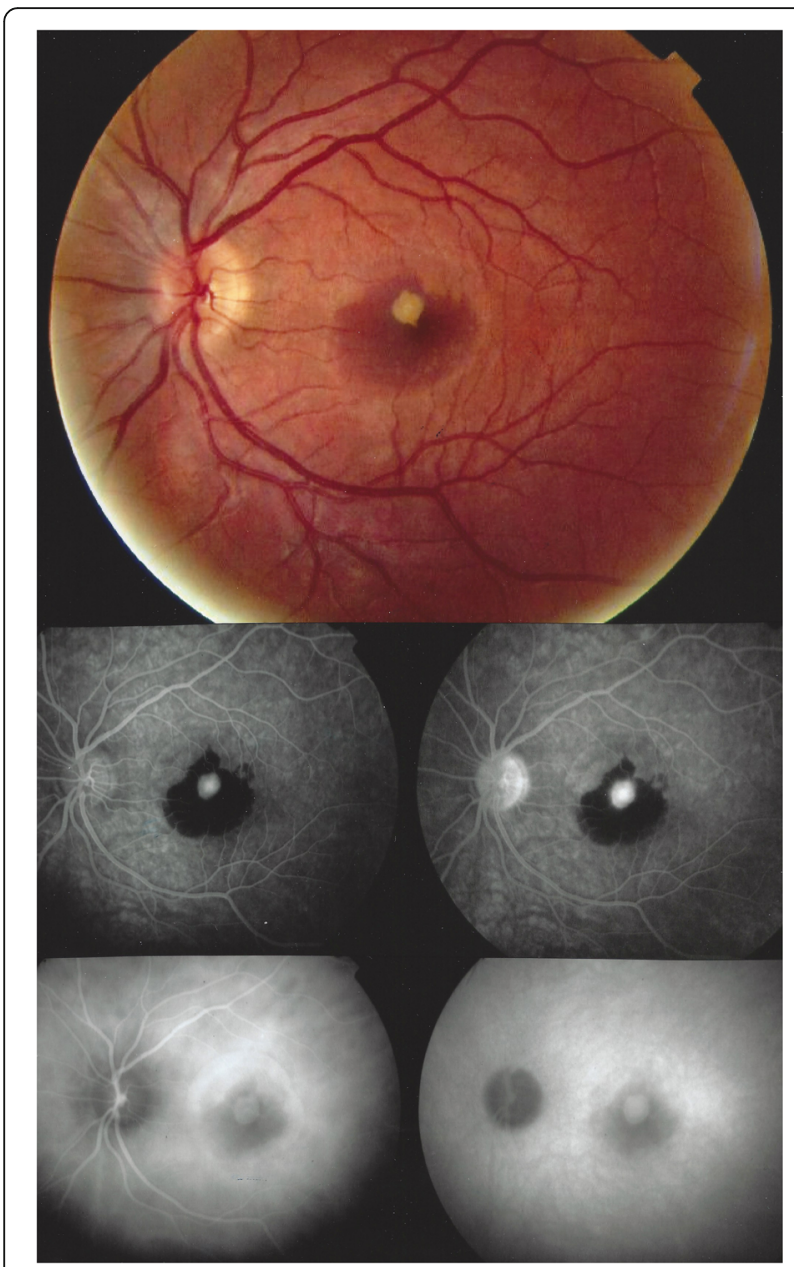

Fig. 4 Inflammatory CNVs in a 16-year-old youngster. Fundus (top) shows the CNVs with an intraretinal haemorrhage. FA (middle) shows the bright hyperfluorescent CNVs, also hyperfluorescent on ICGA (bottom). A few days later, a repeat ICGA showed the typical ICGA signs of MEWDS (see Fig. 9) hypofluorescent areas is hypo or non-perfusion of the choriocapillaris and cannot correspond to the alleged non-fixation of the ICGA molecule on hypothetically damaged RPE cells which is a pure conjecture. Indeed, an in-vitro study showed the opposite indicating increased infrared fluorescence in damaged RPE cells [53]. In clinical situations also, such as granulomatous chorioretinitis, diseased areas in the periphery accumulate ICGA and appear as hyperfluorescent pinpoints [54] (Fig. 8).

ICGA, together with BL-FAF is by far the most important imaging modality to ascertain the diagnosis of MEWDS and is also the best way to establish the extent of the lesion process and to explain the severity of visual impact. It used to be the most useful follow-up parameter but is today advantageously replaced by BL-FAF, as it is a non-invasive method. ICGA is rarely useful to detect MEWDS as the origin of inflammatory CNVs (Figs. 4 \& 9) [41].

\section{Spectral-domain optical coherence tomography (SD-OCT)}

The SD-OCT appearance of MEWDS is that of disruption mainly of the ellipsoid zone (EZ-photoreceptor outer segments) and interdigitation zone (IZ) complex in the fovea (Fig. 10) and outside it is sometimes associated with reflective focal lesions that crossed the external limiting membrane line. As these lesions are very demonstrative and cause impressive secondary signs such as BL-FAF hyperautofluorescence many reports situate the origin of the disease in these structures, although they only represent the consequence of ischaemia due to choriocapillaris non-perfusion [3, 7, 30]. The peripheral lesions consist of larger EZ discontinuity or disruption defined "spots". The spots have been recognized with adaptive optics scanning laser ophthalmoscopy (AOSLO) as areas with absence of the photoreceptor outer segments $[55,56]$. All the foveal and peripheral lesions 7- $\quad$ spontaneously resolve with time with small areas of focal ). RPE atrophy in the most severe cases [57]. SD-OCT The only possible explanation for these combined with decreased near-infrared fundus

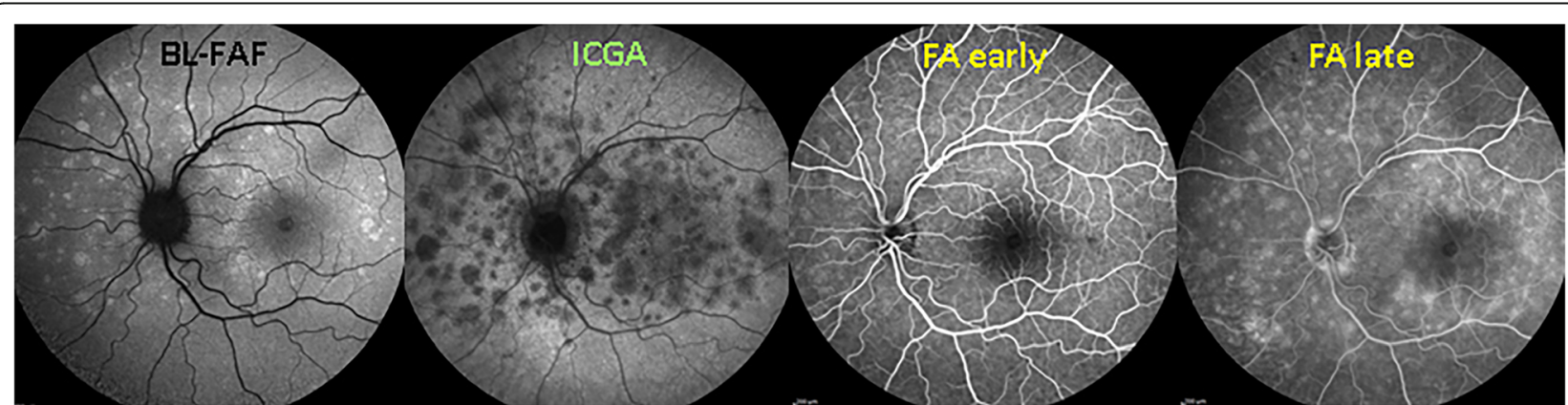

Fig. 5 FA in MEWDS. FA signs in a MEWDS patient in the acute phase. BL-FAF picture (left) and ICGA (second from left) show typical disease signs. Early FA (second from right) shows very faint hyperfluorescence while late FA shows more distinguishable hyperfluorescent areas (right) 

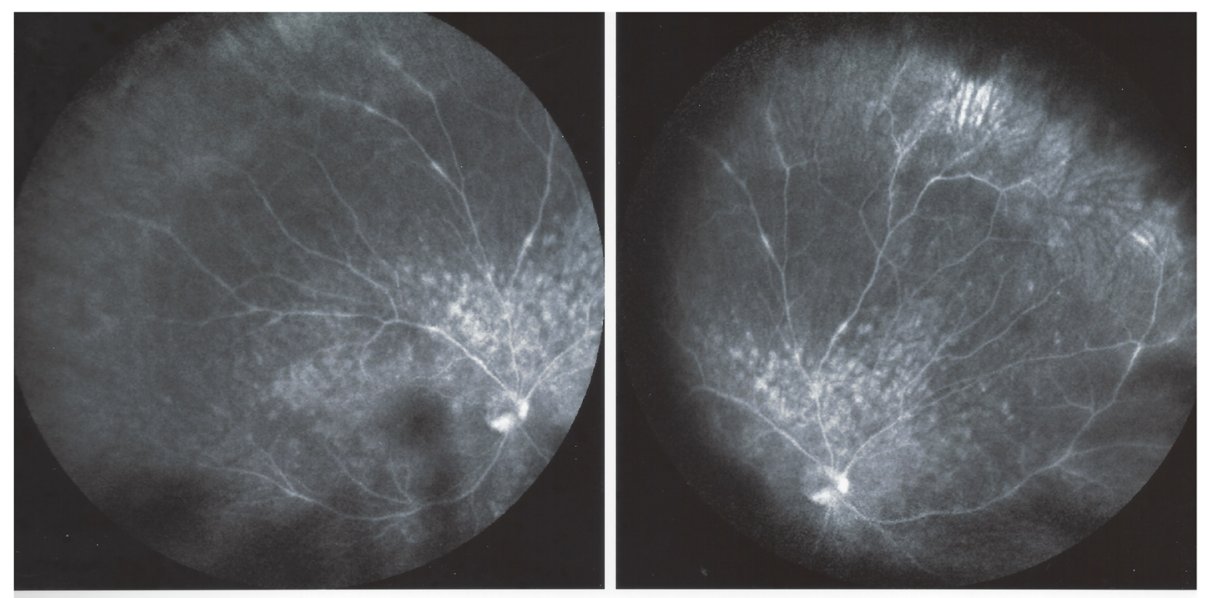
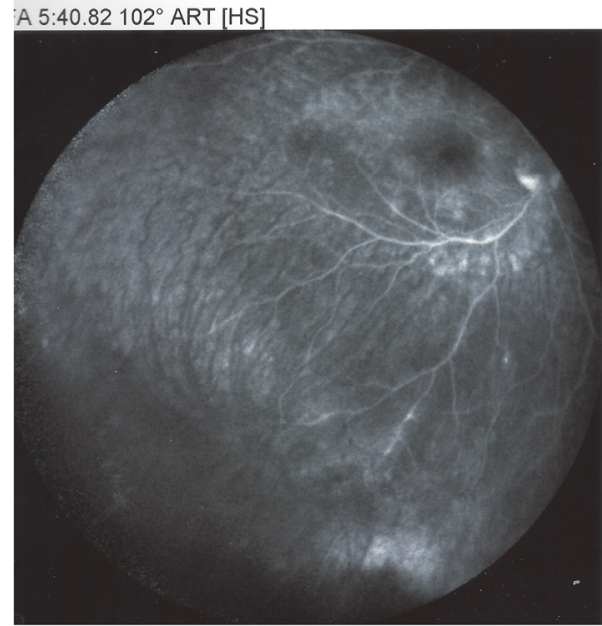

FA $6: 11.79102^{\circ}$ ART [HS]

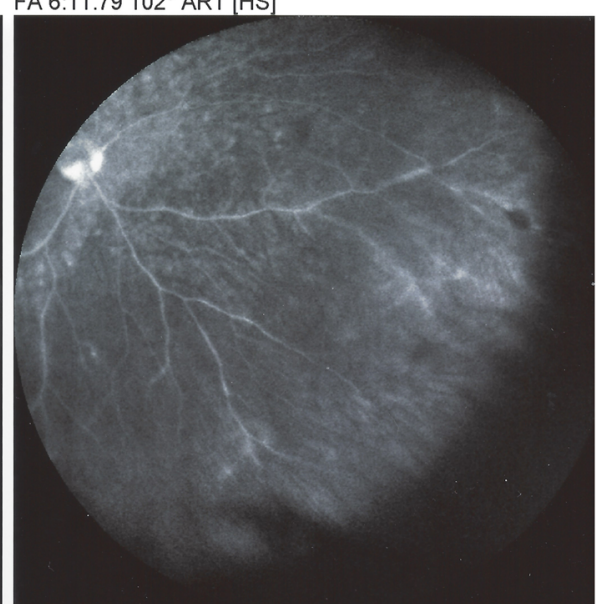

Fig. 6 Retinal vasculitis in MEWDS. FA showing patchy hyperfluorescent area in the posterior pole as well as peripheral retinal vasculitis. (same patient as in Fig. 7)

autofluorescence (NIR-FAF) was shown to characterise foveal granularity [2]. The choroidal thickness can increase in the acute phase of MEWDS and go back to normal in the recovery phase [58].

\section{Blue-light fundus autofluorescence (BL-FAF)}

BL-FAF imaging is a technique that became available recently for assessing the RPE function and the integrity of the chorioretinal interface. It is generated from the bisretinoids of lipofuscin in the RPE cells [59]. This material, the major fluorophores in the eye, is a mixture of several bisretinoids (A2E, A2PE) that are by-products of the visual cycle. These bisretinoids form primarily in the photoreceptor outer segments and are deposited secondarily in the RPE cell lysosomes during the process of photoreceptor outer segment phagocytosis [60, 61]. The intensity of the autofluorescent signal is modified by the variation of the amount of fluorophores and by the absorption of light by macular pigments and by photopigments in the photoreceptor outer segments [62]. Under normal conditions, visual photopigments absorb the exciting blue light, thereby attenuating the autofluorescent signal coming from the RPE. In MEWD $\mathrm{S}$, active disease is reflected by bright autofluorescent patterns that become isoautofluorescent after photobleaching with blue light [63] (Fig. 11).

This indicates that the hyperautofluorescence originates from the loss of photoreceptor outer segments with consequent reduction of the photopigment density causing a better visualization of natural background autofluorescence [64]. This is especially significant because sometimes fundoscopy shows absence of pathology (Figs. 3 \& 11) and fluorescein angiography may not be relevant. BL-FAF imaging represents a useful, fast, noninvasive and very sensitive diagnostic technique to evaluate inflammatory disorders affecting the chorioretinal interface. Wide-field BL-FAF is useful to give global view of the diseased areas (Fig. 12). The fact that BL-FAF 


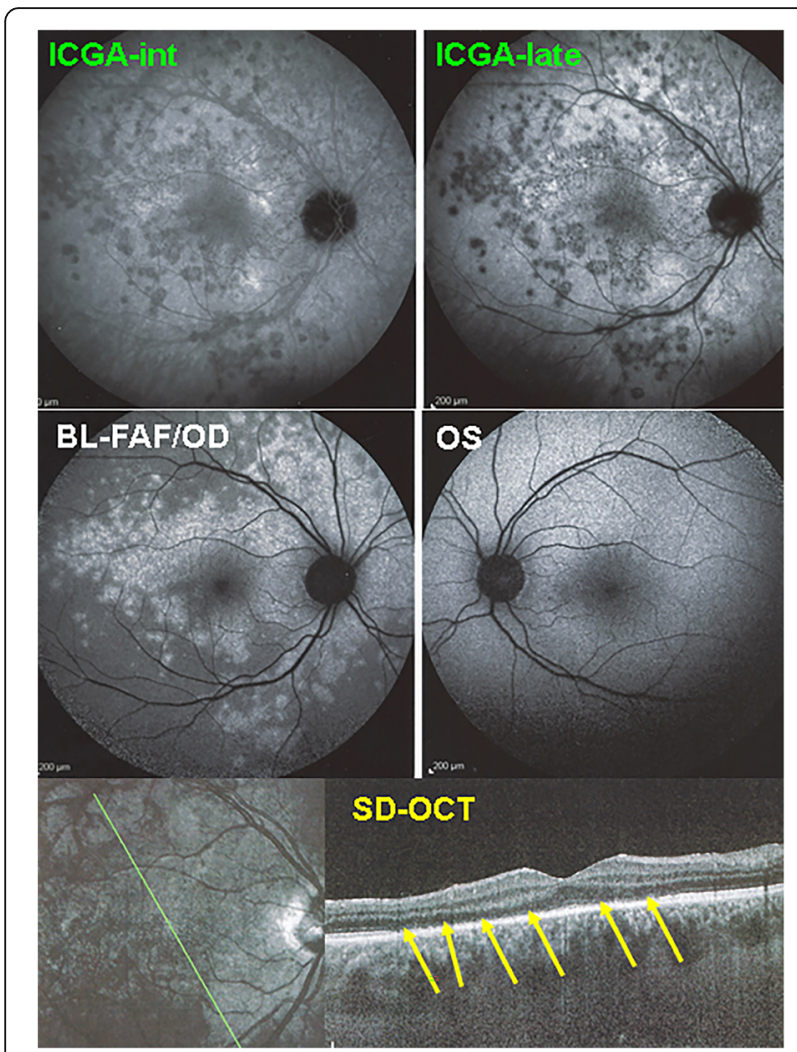

Fig. 7 ICGA in MEWDS. ICGA hypofluorescence is present in the intermediate angiographic phase (top left) and more clearly detected in the late phase (top right). It co-localises with BL-FAF hyperautofluorescent areas (middle left) and corresponds to loss or damage of photoreceptor outer segments (bottom, yellow arrows)

exactly co-localises with ICGA hypofluorescent areas, indicating non-perfusion, supports the fact that photoreceptor outer segment damage results from consequent ischaemia.

\section{Optical coherence tomography angiography (OCT-A)}

Since several years optical coherence tomography angiography has been proposed to examine several intraocular vascular pathologies including choriocapillaritis entities characterised by choroidal/choriocapillaris nonperfusion which appeared on OCT-A as vascular dropouts. For MEWDS, several reports seemed to indicate that the choriocapillaris was intact and hence these reports concluded that the only damaged structure was the outer retina $[30,65,66]$. The principle on which OCT-A is based on is called diffractive particle movement detection performed by sequential OCT B-scans, so identifying vascular flow. However, in end-capillaries, suspected to be at the origin of MEWDS, there is practically no flow and capillary drop-out cannot be detected as it is possible for choriocapillaritis entities such as APMPPE where larger vessels are involved [67]. Even in MEWDS the degree of vascular choroidal non-perfusion can differ from one case to another and there are also reports of capillary drop-outs probably found in more severe cases of MEWDS [51, 68]. On the other hand, absence of perfusion and hence absence of the ICG dye in these areas can perfectly well be identified by ICGA. Therefore, unlike in other choriocapillaritis entities such as APMPPE, MFC and serpiginous choroiditis (SC), OCT-A is probably inappropriate for most MEWDS cases, as it is unable to detect whether there is choriocapillary drop out or not.

\section{Clinicopathology of MEWDS}

MEWDS has been included in the past in a nebula called "white dot syndromes" (WDS), simply based on the resembling appearance of the fundus aspect of the diverse disease entities included by the first promoters of this terminology [21]. In those times it was a meritorious effort to attempt to bring more clarity in these clinical entities difficult to understand. However, this purely phenomenological approach brought together disease entities that, apart from a similar aspect, had nothing in common. This approach was understandable since the tools were not available for a more detailed analysis of the actual clinicopathology of these diverse diseases. The methodology applied, based on observation, had prevailed for years, and was at the origin of so many accurate disease characterisations, describing new individual disease entities [14, 17, 19, 22], but was inappropriate when using it to attempt to explain disease mechanisms and disease classifications. Diseases listed in the group of WDSs in 1995, all choroidal inflammatory diseases, were included at a time when imaging exploration of the choroid was still very limited. In the mid-1990s, ICGA became available and allowed to investigate more precisely the choroid and understand clinicopathological mechanisms of choroidal inflammatory diseases. ICGA allowed to sort out diseases predominantly involving the choroidal stroma, such as Vogt-Koyanagi-Harada (VKH) disease and HLA-A29 birdshot retinochoroiditis on one side and those that involved predominantly the choriocapillaris such as MEWDS, APMPPE, MFC and SC on the other side [24]. Several publications, past and present, classified MEWDS in the sub-group of primary inflammatory choriocapillaropathies $[13,69,70]$. In 2016, a divergent hypothesis on the pathogenetic mechanism of MEWDS was proposed, speaking of a primary "photoreceptoritis" [30]. Indeed, the photoreceptor layer is damaged in MEWDS and photoreceptor loss is at the origin of the typical BL-FAF hyperautofluorescent areas seen on BL-FAF, characterising MEWDS. However, this layer is only damaged secondarily, due to choriocapillaritis. The assumption of a primary photoreceptoritis was based on a misinterpretation of ICGA findings by the authors and on an alleged integrity of the 


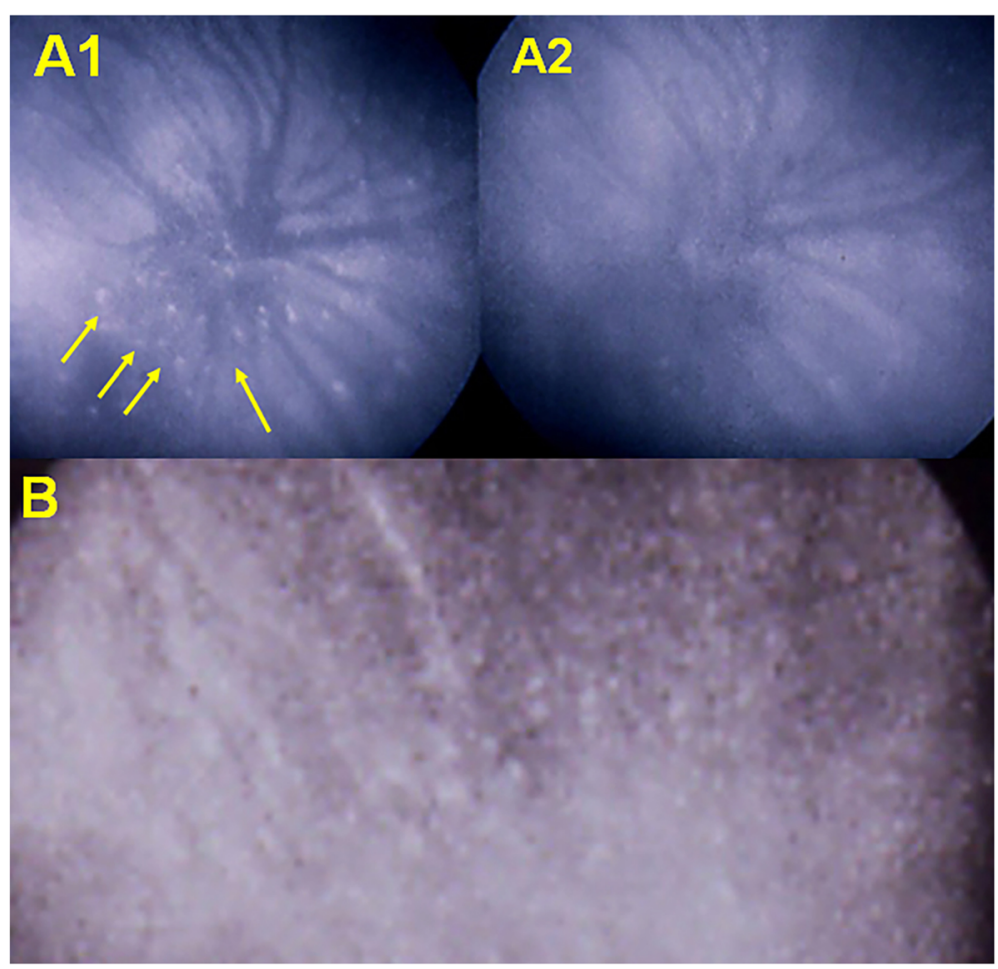

Fig. 8 ICGA of peripheral pinpoints in granulomatous chorioretinitis. Diseased areas hyper-fix the ICG molecule and are not hypofluorescent as pretended by some. On the contrary they constitute hyperfluorescent pinpoint, in tuberculous chorioretinitis at presentation (A1) with disappearance after treatment (A2); and sarcoidosis chorioretinitis B where numerous diseased hyperfluorescent pinpoints are visible

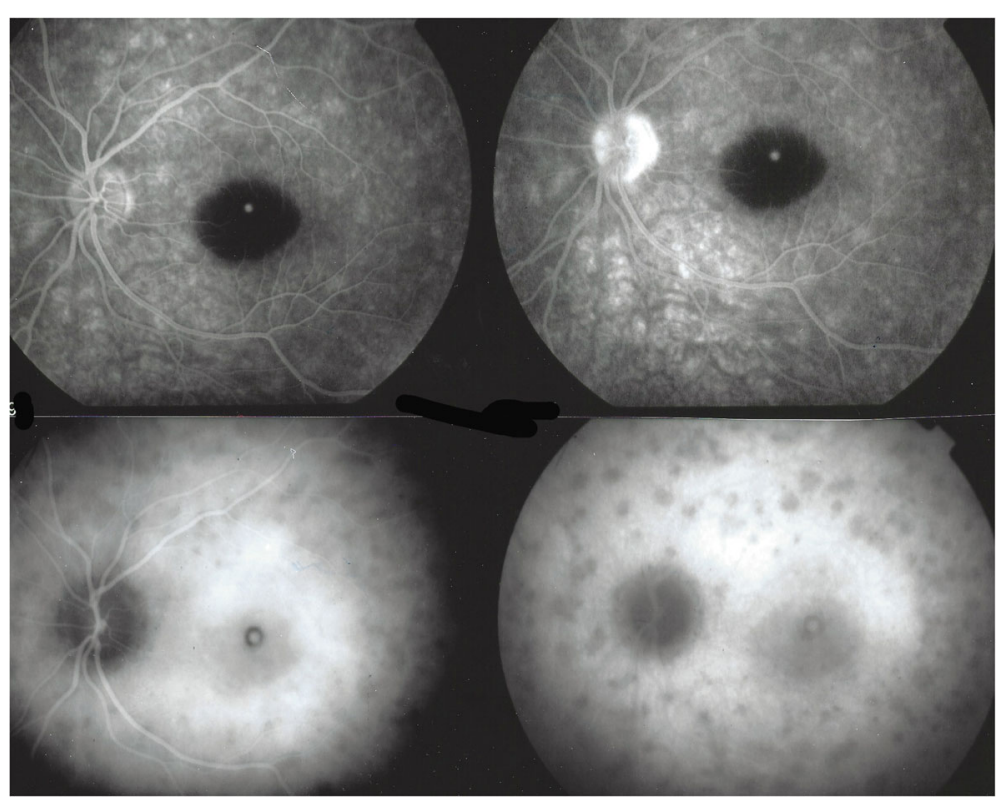

Fig. 9 Inflammatory CNVs in a 16-year-old youngster before outbreak of MEWDS (same patient as Fig. 4). Ten days after intravitreal anti-VEGF injection, the CNVs are markedly reduced and appearance of slight FA hyperfluorescent areas (top) and typical areas of hypofluorescence on ICGA in the intermediate phase (bottom left) and more clearly visible in the late angiographic phase (bottom right) 


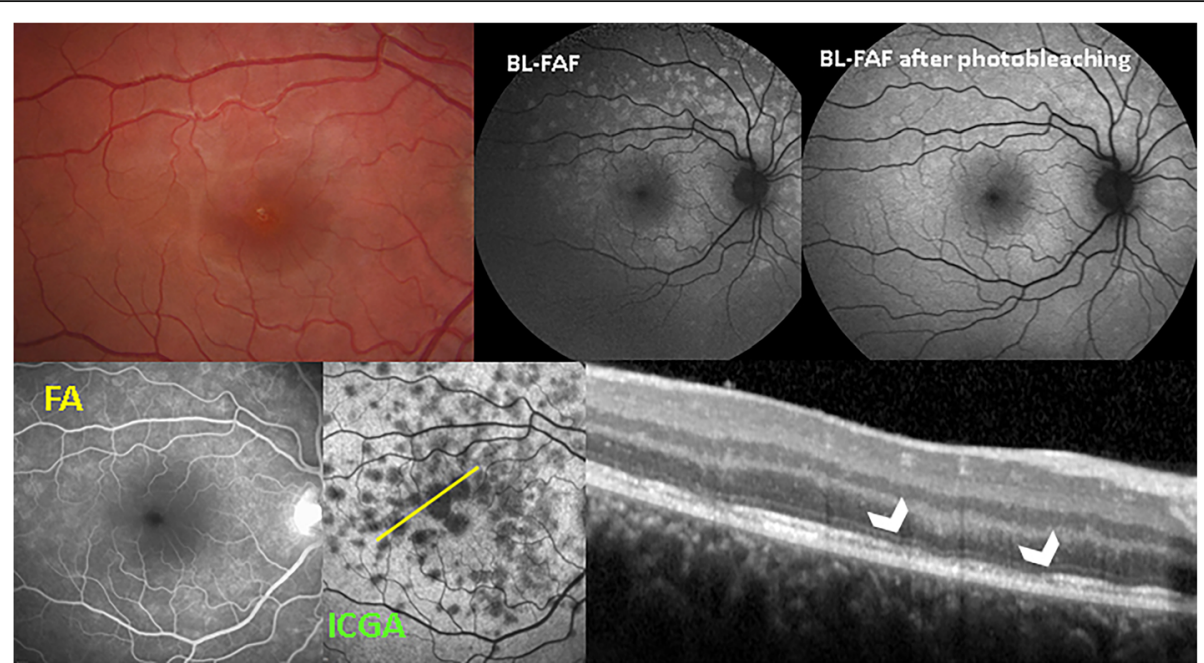

Fig. 10 SD-OCT images in MEWDS. Fundoscopy and SD-OCT in a patient with foveal granularity. In the acute phase (top images) fundus photography reveals foveal granularity the only fundus finding. SD-OCT of the fovea shows attenuation of the ellipsoid zone (photoreceptors) (red arrow) and absence of the interdigitation zone (blue arrow). In the convalescent phase (bottom images) fundus photography and SD-OCT are back to normal

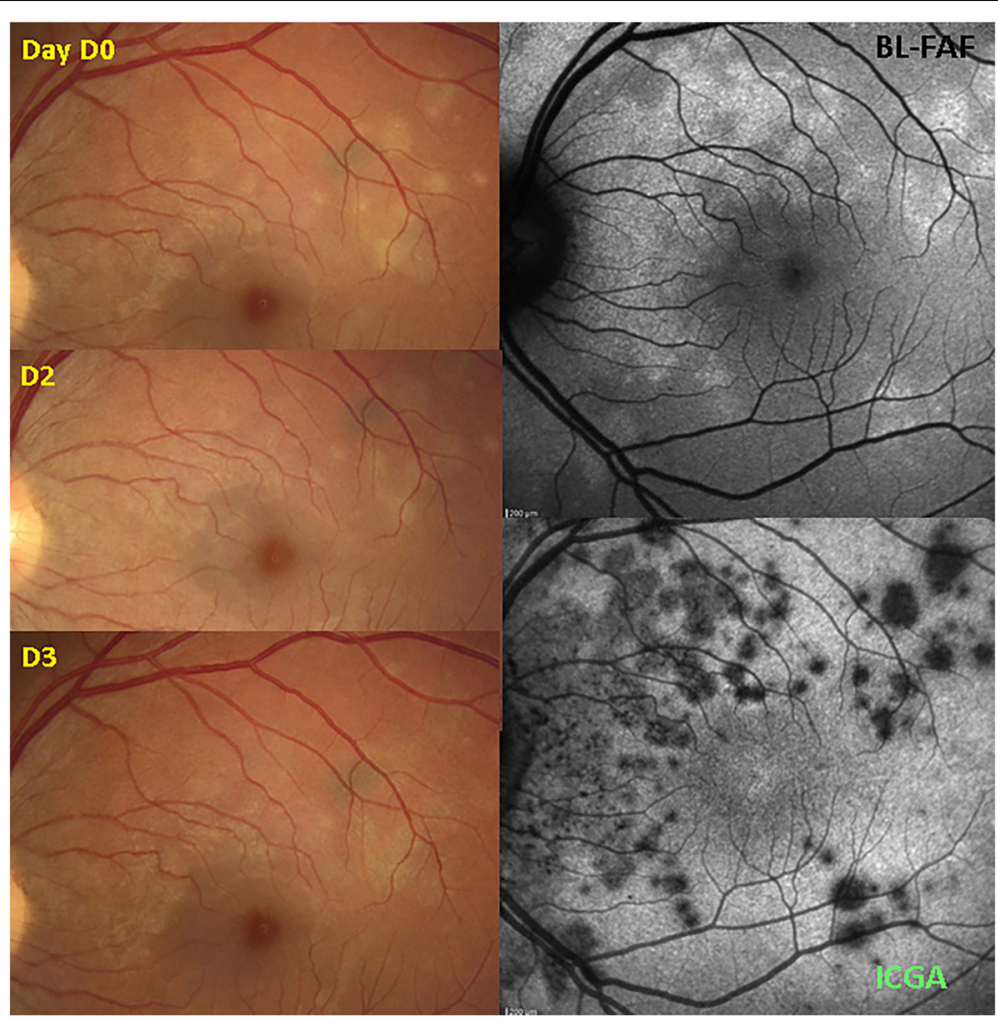

Fig. 11 SD-OCT / BL-FAF / FA / ICGA signs of MEWDS. Patient with a 4-day history of photopsias in right eye. Fundus photography does not show any pathology. BL-FAF shows areas of hyperautofluorescence due to loss of photoreceptor outer segments. Photobleaching performs loss of photopigment in the rest of the fundus (top right). FA (bottom left) shows very faint hyperfluorescence while ICGA (bottom middle) clearly delineates diseased areas. SD-OCT shows interruption of the ellipsoid zone (arrowheads) corresponding to the ICGA hypofluorescent areas 


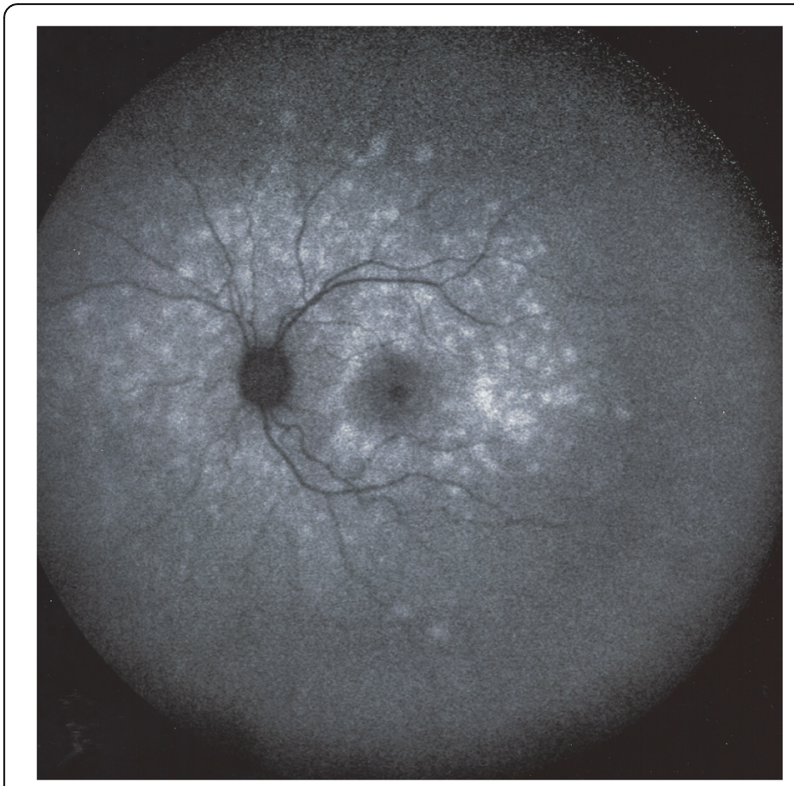

Fig. 12 BL-FAF wide-field in a typical MEWDS case. Global display of hyperautofluorescent area on a wide-field picture

choriocapillaris on OCT-A, which was rectified in an editorial [71]. In fact, OCT-A which is based on flow do not detect end-capillary low flow vessels of the choriocapillaris and hence is unable to detect whether there is flow or not, while ICGA is able to detect non-perfusion by showing ICG hypofluorescence [71]. Depending on the extent of choriocapillaris involvement, a recent report showed that there was indeed choriocapillaris dropout when analysed by Swept Source OCT-A [68]. Another report identified choriocapillaris flow deficit in MEWDS patients and interestingly showed that in $7 / 34$ patients with overlapping multifocal choroiditis were identified to have these changes, speaking for a common mechanism in these two choriocapillaritis entities [72]. Moreover, there is a variability of degrees of choriocapillaris involvement in MEWDS cases determining diverse OCT-A findings and different FA and ICGA features depending on the severity degree [73].

There are additional arguments to those exposed in the editorial by Lages et al., that are speaking for primary choriocapillaritis in MEWDS [71], including the implication of the choroid in MEWDS shown in numerous reports that cannot be ignored [58, 74-76]. Furthermore, diverse vaccinations were shown to trigger both MEWD $S$ [77] and APMPPE cases [78]. It is most improbable that a vaccine induced immune reaction would directly target the photoreceptors in one case (MEWDS) and the choriocapillaris in the other (APMPPE). The most commonly suspected mechanism is an immune induced choriocapillaritis in both cases, which, following pioneering pragmatism, is also the mechanism suspected in
MEWDS and other choriocapillaritis cases often preceded by flu-like viral symptoms. In a recent case report, interestingly, a patient initially diagnosed as MEWDS turned out to be an acute syphilitic posterior placoid chorioretinopathy (Fig. 13) (ASPPC) [79], a disease characterised by damage to photoreceptors due to choriocapillaritis [46].

After the publication of Pichi et al., several publications interpreted photoreceptor damage, a real and constant finding in MEWDS, as a primary involvement. All these studies failed to perform ICGA that could have shown choriocapillaris nonperfusion not apparent on OCT-A [33, 66]. In contrast, a perfect example of primary outer retinal, photoreceptor disease (photoreceptoritis) is represented by acute zonal occult outer retinopathy (AZOOR) [80, 81].

\section{Differential diagnosis and practical diagnostic criteria of MEWDS}

MEWDS is a disease sometimes difficult to diagnose. As its name indicates, the characteristic fundal white dots are evanescent and may not be present any more when the patient consults with some delay after the onset of symptoms. Several clinical elements are helpful in the diagnosis, including a flu-like viral episode preceding symptoms (photopsias and subjective scotomas), fundal yellow-white dots, granularity of the fovea, very variable decrease of visual acuity and visual field impairment that can both be very severe depending on the degree of severity of choriocapillaris non perfusion [1, 2,9]. Multimodal imaging has contributed significantly to an easier diagnosis. Fluorescein angiography, showing discreet hyperfluorescence in the involved areas is not the most useful method characterising MEWDS. However, the combination of ICGA, BL-FAF and SD-OCT represent an extremely forceful triad complementing clinical findings in the diagnosis of MEWDS [82]. ICGA hypofluorescence was found to delineate exactly the diseased areas indicating choriocapillaris hypo or non-perfusion. Interestingly, these hypofluorescent areas are still detectable when patients consult late, after the fundus lesions have vanished, allowing to make the diagnosis retroactively $[6,7,83]$. Since BL-FAF has come into use, BLFAF-hyperautofluorescence marked the diseased areas co-localising with ICGA hypofluorescence and proved to be a marker at least as good as ICGA to detect MEWDS lesions, being especially useful for the follow-up as it is a non-invasive modality [84-86]. Hyperautofluorescence on BL-FAF is explained by the loss of the photoreceptor photopigment screen unmasking the normal underlying RPE autofluorescence [82]. This morphological change is apparent on SD-OCT, showing loss of photoreceptor outer segments corresponding to the areas where BLFAF hyperautofluorescence and ICGA hypofluorescence 


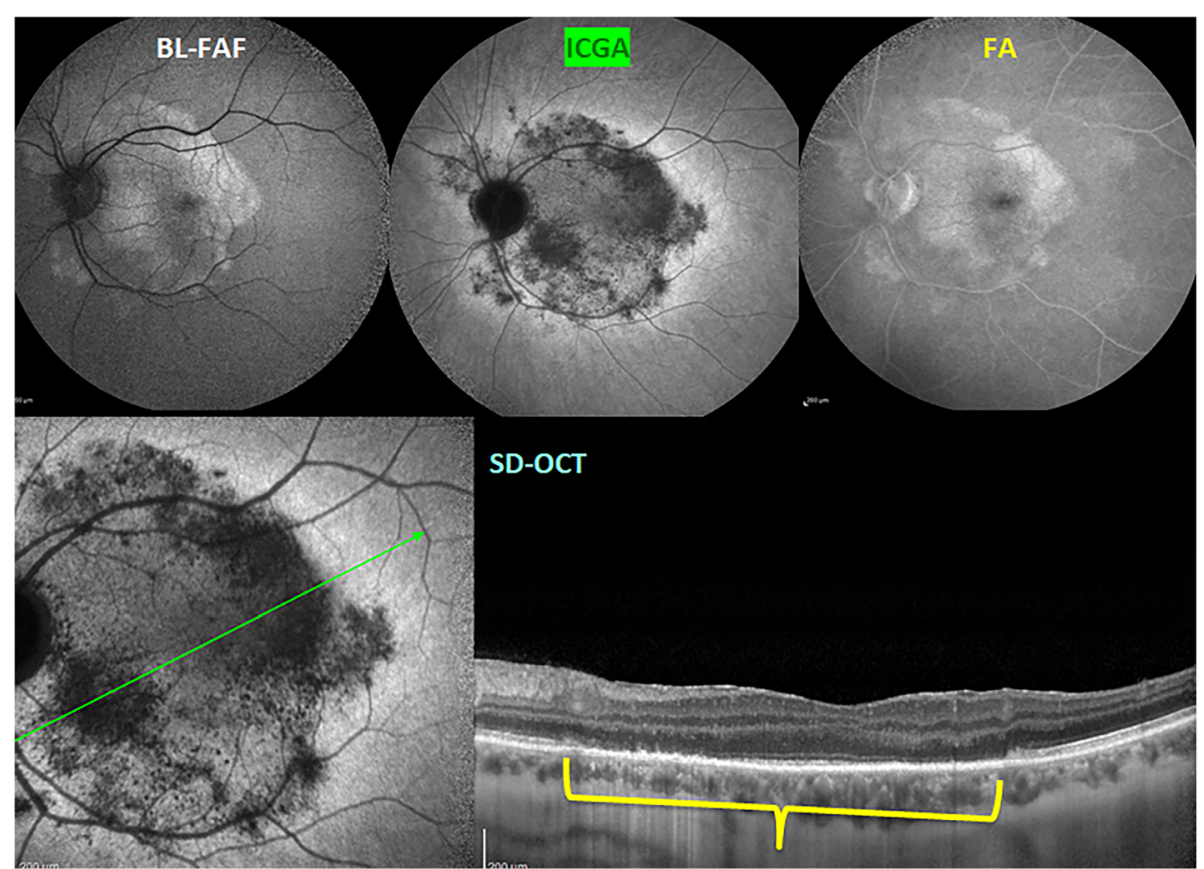

Fig. 13 Masquerade of MEWDS. Case of acute syphilitic posterior placoid mimicking MEWDS. BL-FAF (top left) shows a placoid area of hyperautofluorescence. ICGA late frame (top middle) shows a hypofluorescent dark area due to choriocapillaris hypo and/or non-perfusion. FA late frame (top right) shows retinal staining probably caused by reactive exudation due to ischaemia of external retina. SD-OCT scan through macular area shows loss of photoreceptor outer segments (yellow bracket) Green line on ICGA frame (bottom left) shows the orientation of the SD-OCT scan (bottom right)

are localised $[87,88]$. Based on these imaging modalities clear diagnostic criteria can be elaborated (Table 2).

Recently, "classification criteria" resulting from a sophisticated, "machine learning" and statistical process, have been proposed [31]. This is an appreciable intellectual effort but to no avail, similar to other "classification criteria" of other posterior uveitis entities reported by the same group because they lack practical usefulness as both ICGA and BL-FAF, the most sensitive modalities to detect MEWDS lesions, failed to be included. SD-OCT, as explained in this attempt, can indeed show the lesions at the level of the outer retina but the pattern of lesions needs to be globally displayed by ICGA, and/or by BL-

Table 2 Diagnostic criteria for MEWDS

1. Photopsias and/or subjective scotomas at or prior to presentation
and/or preceding flu-like episode
2. Triad of ICGA hypofluorescent and BL-FAF hyperautofluorescent areas
and corresponding loss or damage of ellipsoid zone on SD-OCT ${ }^{\mathrm{a}}$
3. Multiple yellow-white fundus dots and/or foveal granularity (helpful $^{\mathrm{a}}$
but moderate to low sensitivity)
4. Unilateral clinical involvement ${ }^{\mathrm{b}}$ (helpful)
5. Exclusion of other infectious, inflammatory or masquerading entities
6. Scotomas and/or enlarged blind spot-on visual field
7. Often young myopic women ${ }^{\mathrm{b}}$

assential needed criteria

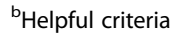

FAF in case of unavailability of ICGA. In practice, these two determining imaging modalities are essential today to diagnose MEWDS and other choriocapillaritis entities [24] and they have been omitted in the recently proposed classification criteria based on a quite limited number of cases [31].

The main clinical differential diagnosis that the practitioners may encounter is retrobulbar optic neuritis in case of extensive visual field deficit. We received more than one referred patient with this diagnosis. A typical case history is exposed on Fig. 1. This patient was sent with the diagnosis of retrobulbar neuritis. When applying the diagnostic triad of ICGA, BAF and SD-OCT the diagnosis of MEWDS was easily performed (Fig. 1). Another differential diagnosis within choriocapillaritis entities is idiopathic multifocal choroiditis (MFC), as MEWDS and MFC have the same features using the diagnostic triad of ICGA, BAF and SD-OCT [88, 89]. MFC can present initially as MEWDS and when the disease evolves with recurrences or becomes bilateral with chorioretinal scars the diagnosis has to be redirected towards MFC [12]. It is difficult to make the difference between whether MEWDS and MFC are overlapping syndromes or whether the first MFC episode presents with MEWDS features, only the evolution permitting to specify the ultimate diagnosis [12]. Acute idiopathic blind spot enlargement (AIBSE) has been linked to 
MEWDS. The visual field changes have been found to correspond to peripapillary hypofluorescence as those seen in MEWDS when ICGA was performed [25, 27, 90, 91]. The topic on overlapping and masquerade syndromes will be dealt with in more details in the next section.

\section{Overlapping syndromes and masquerades of MEWDS}

An overlap between MEWDS and other inflammatory choriocapillaropathies, especially MFC which includes punctate inner choroidopathy (PIC), has been reported involving the ipsilateral or contralateral eyes [12, 89]. Kang et al. [72] have recently compared the clinical characteristics of 27 patients with classic MEWDS and 7 patients with atypical MEWDS overlapping with MFC, involving the same eye in 5 and contralateral eye in 2 of them. While there was no significant difference in the demographic features, presenting symptoms, refractive error, intraocular inflammation, lesion distribution, or time to resolution, RPE hyperpigmentation and focal choroidal excavation were seen exclusively in those with overlapping MFC. Additionally, atypical cases had a thicker choroid at presentation, and the presence of subfoveal MFC significantly influenced the final visual acuity [72]. Essilfie et al. [92] have recently described 17 cases with "secondary" MEWDS, 15 of them having preexisting or late onset MFC lesions. Final visual acuity was $20 / 20$ in all cases, except 2 patients with macular CNVs [92].

Many conditions that masquerade as MEWDS have been reported principally based on clinical examination [93]. However, when considering strict diagnostic criteria including, in addition to clinical signs and symptoms, unilaterality, the triad of ICGA, BL-FAF and SD$\mathrm{OCT}$, in several of these conditions MEWDS can be ruled. For instance, AZOOR which shows similar BLFAF and SD-OCT signs has preserved choriocapillaris not presenting ICGA hypofluorescent areas [81]. Of the 13 patients reported as masquerading MEWDS, two conditions, syphilis, in particular ASPPC, and MFC, occurring in five reported patients, cause a real differential diagnostic problem as the clinicopathological mechanism is comparable $[46,72,79]$.

\section{Conclusion}

Today MEWDS can be diagnosed with a high degree of certainty thanks to more recent imaging modalities such as ICGA, BL-FAF and SD-OCT in complement of the clinical examination. The diagnostic criteria as exposed in this article represent a highly practical tool not only to diagnose MEWDS but also to follow the evolution of lesions. The latter point is important, as, albeit MEWDS has usually a spontaneously favourable evolution, the diagnostic and monitoring approach exposed here can spot the rare cases which do not have a resolutive evolution or which have an overlapping evolution to MFC. Such precise diagnostic criteria are also practically helpful to exclude other diagnoses such as retrobulbar neuritis which is often posed in non-diagnosed MEWDS cases.

\section{Abbreviations}

MEWDS: Multiple evanescent white dot syndrome; BL-FAF: Blue-light fundus autofluorescence; ICGA: Indocyanine angiography; SD-OCT: Spectral domain optical coherence tomography; IS/OS: Inner segment/ outer segment; OCTA: OCT angiography; MFC: Idiopathic multifocal choroiditis; APMPPE: Acute posterior multifocal placoid pigment epitheliopathy; ASPPC: Acute syphilitic posterior placoid chorioretinitis; AZOOR: Acute zonal occult outer retinopathy; RPE: Retinal pigment epithelium; AMIC: Acute multifocal choriocapillaritis; WDS: White dot syndromes; AIBSE: Acute idiopathic blind spot enlargement; CNVs: Choroidal neovascularisation; VF: Visual Fields; IZ: Interdigitation zone; EZ: Ellipsoid zone; AOSLO: adaptive optics scanning laser ophthalmoscopy; NIR-FAF: Near-infrared fundus autofluorescence; SC: Serpiginous choroiditis; PICCPs: Primary inflammatory choriocapillaropathies; VKH: Vogt-Koyanagi-Harada; FA: Fluorescein angiography; PIC: Punctate inner choroidopathy

\section{Acknowledgments}

n/a

Institutional review board statement

n/a.

\section{Informed consent statement}

$n / a$,

\section{Authors' contributions}

"Conceptualization, CPH.; methodology, CPH; software: IP, CPH, AM, ITT; validation, $\mathrm{CPH}, \mathrm{AM}$, IP, ITT.; formal analysis, $\mathrm{CPH}, \mathrm{AM}, \mathrm{IP}, \mathrm{ITT}$; resources, $\mathrm{CPH}_{i}$; data curation, $\mathrm{CPH}, \mathrm{AM}, \mathrm{IP}$, ITT; writing - original draft preparation, $\mathrm{CPH}$ AM,ITT; writing - review and editing, CPH, AM, IP, ITT; visualization, CPH, AM, ITT; supervision, $\mathrm{CPH}$.; project administration, $\mathrm{CPH}, \mathrm{AM}$, IP, ITT; All authors have read and agreed to the submitted version of the manuscript.

Funding

This research received no external funding.

\section{Declaration}

Competing interests

The authors declare no conflict of interest.

\section{Author details}

${ }^{1}$ Retinal and Inflammatory Eye Diseases, Centre for Ophthalmic Specialized Care (COS), Clinic Montchoisi Teaching Centre, Rue Charles-Monnard 6, $\mathrm{CH}-1003$ Lausanne, Switzerland. ${ }^{2}$ Department of Ophthalmology, Valduce Hospital, Como, Italy. ${ }^{3}$ Department of Ophthalmology, Istanbul University, Istanbul Faculty of Medicine, Istanbul, Turkey.

Received: 11 October 2021 Accepted: 29 November 2021

Published online: 18 December 2021

\section{References}

1. Herbort CP Jr (2016) Multiple Evanescent White Dot Syndrome (MEWDS). In: Zierhut M, Pavésio C, Ohno S, Oréfice F, Rao NA (eds) Intraocular Inflammation. Springer, Berlin Heidelberg, pp 997-1005

2. Mantovani A, Invernizzi A, Staurenghi G, Herbort CP Jr (2019) Multiple evanescent white dot syndrome: a multimodal imaging study of foveal granularity. Ocul Immunol Inflamm 27(1):141-147. https://doi.org/10.1080/ 09273948.2017.1353104

3. Marsiglia M, Gallego-Pinazo R (2016) Cunha de Souza E, Munk MR, Yu S, Mrejen S, Cunningham ET Jr, Lujan BJ, Goldberg NR, Albini TA, Gaudric a, 
Francais C, Rosen RB, Freund KB, Jampol LM, Yannuzzi LA. Expanded clinical spectrum of multiple evanescent white dot syndrome with multimodal imaging. Retina 36(1):64-74. 26166804. https://doi.org/10.1097/AAE. 0000000000000685

4. le D, Glaser BM, Murphy RP, Gordon LW, Sjaarda RN, Thompson JT (1994) Indocyanine green angiography in multiple evanescent white-dot syndrome. Am J Ophthalmol 117(1):7-12. 8291595. https://doi.org/10.1016/ s0002-9394(14)73008-9

5. Obana A, Kusumi M, Miki T (1996) Indocyanine green angiographic aspects of multiple evanescent white dot syndrome. Retina 16(2):97-104. 8724951. https://doi.org/10.1097/00006982-199616020-00002

6. Desarnaulds AB, Borruat FX, Herbort CP, de Courten C (1998) Indocyanine green angiography in "multiple evanescent white dot syndrome" (MEWDS). Klin Monatsbl Augenheilkd 212(5):318-320. 9677567. https://doi.org/10.1 055/s-2008-1034894

7. Dell'Omo R, Mantovani A, Wong R, Konstantopoulou K, Kulwant S, Pavesio CE (2010) Natural evolution of fundus autofluorescence findings in multiple evanescent white dot syndrome: a long-term follow-up. Retina 30(9):14791487. 20588204. https://doi.org/10.1097/IAE.0b013e3181d50cd3

8. Sikorski BL, Wojtkowski M, Kaluzny JJ, Szkulmowski M, Kowalczyk A (2008) Correlation of spectral optical coherence tomography with fluorescein and indocyanine green angiography in multiple evanescent white dot syndrome. Br J Ophthalmol 92(11):1552-1557. https://doi.org/10.1136/bjo.2 007.135863 Epub 2008 Jul 9. PMID: 18614567

9. Borruat FX, Othenin-Girard P, Safran AB (1991) Multiple evanescent white dot syndrome [multiple evanescent white dot syndrome]. Klin Monatsbl Augenheilkd 198(5):453-456. https://doi.org/10.1055/s-2008-1046009 PMID: 1886383

10. Hamed LM, Glaser JS, Gass JD, Schatz NJ (1989) Protracted enlargement of the blind spot in multiple evanescent white dot syndrome. Arch Ophthalmol 107(2):194-198. https://doi.org/10.1001/archopht.1989.0107001 0200022 PMID: 2916972

11. Kimmel AS, Folk JC, Thompson HS, Strnad LS (1989) The multiple evanescent white-dot syndrome with acute blind spot enlargement. Am J Ophthalmol 107(4):425-426. https://doi.org/10.1016/0002-9394(89)90669-7 PMID: 2929711

12. Kuznetcova T, Jeannin B, Herbort CP (2012) A case of overlapping choriocapillaritis syndromes: multimodal imaging appraisal. J Ophthalmic Vis Res 7(1):67-75 PMID: 22737390; PMCID: PMC3381111

13. Herbort CP Jr, Mantovani A, Tugal-Tutkun I, Papasavvas I (2021) Classification of Non-Infectious and/or Immune Mediated Choroiditis: A Brief Overview of the Essentials. Diagnostics (Basel) 11(6):939. https://doi.org/10.3390/dia gnostics1 1060939 PMID: 34073914; PMCID: PMC8225100

14. Gass JD (1968) Acute posterior multifocal placoid pigment epitheliopathy. Arch Ophthalmol 80(2):177-185. https://doi.org/10.1001/archopht.1968. 00980050179005 PMID: 5661882

15. Krill AE, Chishti MI, Klien BA, Newell FW, Potts AM (1969) Multifocal inner choroiditis. Trans Am Acad Ophthalmol Otolaryngol 73(2):222-245 PMID: 5771008

16. Nozik RA, Dorsch W (1973) A new chorioretinopathy associated with anterior uveitis. Am J Ophthalmol 76(5):758-762. https://doi.org/10.1016/ 0002-9394(73)90573-4 PMID: 4748195

17. Ryan SJ, Maumenee AE (1980) Birdshot retinochoroidopathy. Am J Ophthalmol 89(1):31-45. https://doi.org/10.1016/0002-9394(80)90226-3

18. Gass JD, Braunstein RA, Chenoweth RG (1990) Acute syphilitic posterior placoid chorioretinits. Ophthalmology 97(10):1288-1297. https://doi.org/10.1 016/S0161-6420(90)32418-1

19. Gass JD (1993) Acute zonal occult outer retinopathy. Donders lecture: the Netherlands ophthalmological society, Maastricht, Holland, June 19, 1992. J Clin Neuroophthalmol 13:79-97

20. Deutman AF, Oosterhuis JA, Boen-Tan TN, Aan de Kerk AL (1972) Acute posterior multifocal placoid pigment epitheliopathy. Pigment epitheliopathy of choriocapillaritis? Br J Ophthalmol 56(12):863-874. https://doi.org/10.113 6/bjo.56.12.863 PMID: 4651978; PMCID: PMC1214795

21. Ben Ezra D, Forrester JV (1995) Fundal white dots: the spectrum of a similar pathological process. Br J Opthalmol 79:856-860. https://doi.org/10.1136/ bjo.79.9.856

22. Jampol LM, Sieving PA, Pugh D, Fishman GA, Gilbert H (1984) Multiple evanescent white dot syndrome. 1. Clinical findings. Arch Ophthalmol 102(5):671-674. https://doi.org/10.1001/archopht.1984.01040030527008
23. Siewing PA, Fishman GA, Jampol LM, Pugh D (1984) Multiple evanescent white dot syndrome. 2. Electrophysiology of the photoreceptors during retinal pigment epithelial disease. Arch Ophthalmol 102(5):675-679. https:// doi.org/10.1001/archopht.1984.01040030531009

24. Herbort CP, Papadia M, Mantovani A (2012) Classification of choroiditis based on inflammatory lesion process rather than fundus appearance: enhanced comprehension through the ICGA concepts of the iceberg and jellyfish effects. Klin Monatsbl Augenheilkd 229(4):306-313. https://doi.org/1 0.1055/s-0031-1299394 Epub 2012 Apr 11. PMID: 22495994

25. Fletcher WA, Imes RK, Goodman D, Hoyt WF (1988) Acute idiopathic blind spot enlargement. A big blind spot syndrome without optic disc edema. Arch Ophthalmol 106(1):44-49. https://doi.org/10.1001/archopht.1988.01 060130050026

26. Hamed LA, Schatz NJ, Glaser JS, Gass JDM (1988) Idiopathic blind spot enlargement without optic disc edema. Arch Ophthalmol 106(8):1030-1031. https://doi.org/10.1001/archopht.1988.01060140182005

27. Pece A, Sadun F, Trabucchi G, Brancato R (1998) Indocyanine green angiography in enlarged blind spot syndrome. Am J Ophthalmol 126(4): 604-607. https://doi.org/10.1016/S0002-9394(98)00123-8

28. Singh K, de Frank MP, Shults WT, Watzke RC (1991) Acute idiopathic blind spot enlargement. A spectrum of disease. Ophthalmology 98(4):497-502. 2052303. https://doi.org/10.1016/s0161-6420(91)32266-8

29. Reddy CV, Brown J Jr, Folk JC, Kimura AE, Gupta S, Walker J (1996) Enlarged blind spots in chorioretinal inflammatory disorders. Ophthalmology 103(4): 606-617. https://doi.org/10.1016/s0161-6420(96)30645-3 PMID: 8618760

30. Pichi F, Srivastava SK, Chexal S, Lembo A, Lima LH, Neri P, Chhablani J, Albini TA, Nucci P, Freund KB, Chung H, Lowder CY, Sarraf D (2016) En face optical coherence tomography and optical tomography angiography of multiple evanescent white dot syndrome: new insights into pathogenesis. Retina 36(Supl 1):S178-S188. https://doi.org/10.1097//AE.0000000000001255

31. SUN Working Group (2021) Classification criteria for multiple evanescent white dot syndrome. Am J Ophthalmol 15(228):198-204. https://doi.org/10.1 016/j.ajo.2021.03.050 Online ahead of print

32. Bosello F, Westcott M, Casalino G, Agorogiannis G, Micciolo R, Rees A, Pavesio C (2020) Multiple evanescent white dot syndrome: clinical course and factors influencing visual acuity recovery. Br J Ophthalmol:317357. https://doi.org/10.1136/bjophthalmol-2020-317357

33. Ramakrishnan MS, Patel AP, Melles R, Vora RA (2021) Multiple evanescent white dot syndrome: findings from a large northern California cohort. Ophthalmol Retina 5(9):850-854. https://doi.org/10.1016/j.oret.2020.11.016

34. Shelsta HN, Rao RR, Bhatt HK, Jampol LM (2011) Atypical presentations of multiple evanescent white dot syndrome without white dots: a case series. Retina 31(5):973-976. https://doi.org/10.1097//AE.0b013e31820a67cc

35. Tavallali A, Yannuzzi LA (2017) MEWDS, common cold of the retina. J Ophthalmic Vis Res 12(2):132-134. https://doi.org/10.4103/jovr.jovr_241_16

36. Hashimoto Y, Saito W, Noda K, Ishida S (2014) Acquired focal choroidal excavation associated with multiple evanescent white dot syndrome: observations at onset and a pathogenic hypothesis. BMC Ophthalmol 14(1): 135. https://doi.org/10.1186/1471-2415-14-135

37. Matsubara H, Uchiyama E, Suzuki K, Matsuda Y, Kondo M (2018) A case of focal choroidal excavation development associated with multiple evanescent white dot syndrome. Case Rep Ophthalmol 9(2):388-394. https://doi.org/10.1159/000492747

38. Wyhinny GJ, Jackson JL, Jampol LM, Caro NC (1990) Subretinal neovascularization following multiple evanescent white-dot syndrome. Arch Ophthalmol 108(10):1384-1385. https://doi.org/10.1001/archopht.1990.01 070120030013

39. Chen KC, Marsiglia M, Dolz-Marco R, Zahid S, Mrejen S, Pulido JS, Cohen SY, Freilich B, Yannuzzi LA, Freund KB (2017) Foveal exudate and choroidal neovascularization in atypical cases of multiple evanescent white dot syndrome. Retina 37(11):2025-2034. https://doi.org/10.1097/IAE. 0000000000001486

40. McCollum CJ, Kimble JA (1992) Peripapillary subretinal neovascularization associated with multiple evanescent white-dot syndrome. Arch Ophthalmol 110(1):13-14. https://doi.org/10.1001/archopht.1992.01080130015007

41. Papadia M, Herbort CP (2010) Idiopathic choroidal neovascularisation as the inaugural sign of multiple evanescent white dot syndrome. Middle East Afr J Ophthalmol 17(3):270-274. https://doi.org/10.4103/0974-9233.65490

42. Mathis T, Delaunay B, Cahuzac A, Vasseur V, Mauget-Faÿsse M, Kodjikian L (2018) Choroidal neovascularisation triggered multiple evanescent white 
dot syndrome (MEWDS) in predisposed eyes. Br J Ophthalmol 102(7):971976. https://doi.org/10.1136/bjophthalmol-2017-311005

43. Burke TR, Addison PKF, Pavesio CE (2021) Multifocal evanescent white dot syndrome-like phenotypes associated with inflammatory and myopic choroidal neovascularization. Ocul Immunol Inflamm 14:1-8. https://doi. org/10.1080/09273948.2021.1936563

44. Cicinelli MV, Hassan OM, Gill MK, Goldstein D, Parodi MB, Jampol LM (2021) A multiple evanescent white dot syndrome-like reaction to concurrent retinal insults. Ophthalmol Retina 5(10):1017-1026. https//doi.org/10.1016/.joret.2020.12.007

45. Ishihara S, Hanada M, Fukasawa A, Tsumura T, lijima H (2007) Automated static perimetry in 5 eyes with multiple evanescent white dot syndrome. Nippon Ganka Gakkai Zasshi 111(7):533-538 Japanese. PMID: 17672051

46. Herbort CP Jr, Papasavvas I, Mantovani A (2020) Choriocapillaris Involvement in Acute Syphilis Posterior Placoid Chorioretinitis is Responsible for Functional Impairment and Points towards an Immunologic Mechanism: A Comprehensive Clinicopathological Approach. J Curr Ophthalmol 32(4):381389. https://doi.org/10.4103/JOCO.JOCO_184_20 PMID: 33553841; PMCID: PMC7861097

47. Papasavvas I, Neri P, Mantovani A, Herbort CP Jr (2021) Idiopathic multifocal choroiditis (MFC): aggressive and prolonged therapy with multiple immunosuppressive agents is needed to halt progression of active disease. An offbeat review and a case series. J Ophthalmic Inflamm Infect submitted. https://doi.org/10.1186/s12348-021-00278-8.

48. Yen MT, Rosenfeld PJ (2001) Persistent indocyanine green angiographic findings in multiple evanescent white dot syndrome. Ophthalmic Surg Lasers 32(2):156-158. PMID: 11300640. https://doi.org/10.3928/1542-8877-2 0010301-14

49. Barile GR, Harmon SA (2017) Multiple evanescent white dot syndrome with central visual loss. Retin Cases Brief Rep 11(Suppl 1):S219-S225. https://doi. org/10.1097/ICB.0000000000000467 PMID: 27824724

50. Schelfhout V, Lafaut B, Van den Neste C, Kestelyn P, De Laey JJ (1998) Multiple evanescent white dot syndrome. Bull Soc Belge Ophtalmol 270:1923 PMID: 9919777

51. Wang JC, Laíns I, Sobrin L, Miller JB (2017) Distinguishing white dot syndromes with patterns of choroidal Hypoperfusion on optical coherence tomography angiography. Ophthalmic Surg Lasers Imaging Retina 48(8): 638-646. https://doi.org/10.3928/23258160-20170802-06 PMID: 28810039

52. Takahashi A, Saito W, Hashimoto Y, Ishida S (2015) Multiple evanescent white dot syndrome associated with retinal vasculitis. Int Med Case Rep J 8: 209-213. https://doi.org/10.2147/IMCRJ.S88639 PMID: 26451125; PMCID: PMC4590319

53. Chang AA, Zhu M, Billson F (2005) The interaction of indocyanine green with human retinal pigment epithelium. Invest Ophthalmol Vis Sci 46(4): 1463-1467. https://doi.org/10.1167/iovs.04-0825 PMID: 15790916

54. Herbort CP, Bodaghi B, Lehoang P (2001) Indocyanine green angiography in ocular inflammatory diseases: principles, schematic interpretation, semiology and clinical value. J Fr Ophtalmol 24(4):423-447 French. PMID: 11351218

55. Boretsky A, Mirza S, Khan F, Motamedi M, van Kuijk FJ (2013) Highresolution multimodal imaging of multiple evanescent white dot syndrome Ophthalmic Surg Lasers Imaging Retina 44(3):296-300. https://doi.org/10.3 928/23258160-20130503-18 PMID: 23676237

56. Labriola LT, Legarreta AD, Legarreta JE, Nadler Z, Gallagher D, Hammer DX, Ferguson RD, Iftimia N, Wollstein G, Schuman JS (2016) Imaging with multimodal adaptive-optics optical coherence tomography in multiple evanescent white dot syndrome: the structure and and the functional relationship. Retin Cases Brief Rep 10(4):302-309. https://doi.org/10.1097/ICB. 0000000000000271 PMID: 26735319; PMCID: PMC4935660

57. Hangai M, Fujimoto M, Yoshimura N (2009) Features and function of multiple evanescent white dot syndrome. Arch Ophthalmol 127(10):13071313. https://doi.org/10.1001/archophthalmol.2009.250

58. Fiore $T$, laccheri B, Cerquaglia A, Lupidi M, Torroni G, Fruttini D, Cagini C (2018) Outer retinal and choroidal evaluation in multiple evanescent white dot syndrome (MEWDS): an enhanced depth imaging optical coherence tomography study. Ocul Immunol Inflamm 26(3):428-434. https://doi.org/1 0.1080/09273948.2016.1231329 Epub 2016 Oct 11. PMID: 27726467

59. Delori F, Keilhauer C, Sparrow JR, Staurenghi G (2007) Origin of fundus autofluorescence. In: Holz FG, Schmitz-Valckenberg S, Spaide RF, Bird AC (eds) Atlas of fundus autofluorescence imaging. Springer, Heidelberg, pp 17-26

60. Staurenghi G, Luiselli C, Levi G, Viola F, Delori FC (2004) Retinal photopigment density measured using autofluorescence imaging. Invest Ophthalmol Vis Sci 45:2795
61. Sparrow JR, Yoon KD, Wu Y, Yamamoto K (2010) Interpretations of fundus autofluorescence from studies of the bisretinoids of the retina. Invest Ophthalmol Vis Sci 41(9):2303-2308. https://doi.org/10.1167/iovs.1 0-5852

62. Theelen T, Berendschot TTJM, Boon CJF, Hoyng CB, Klevering BJ (2008) Analysis of visual pigment by fundus autofluorescence. Exp Eye Res 86(2): 296-304. https://doi.org/10.1016/j.exer.2007.10.022

63. Joseph A, Rahimy E, Freund KB, Sorenson JA, Sarraf D (2013) Fundus autofluorescence and photoreceptor bleaching in multiple evanescent white dot syndrome. Ophthalmic Surg Lasers Imaging Retina 44(6):588-592. https://doi.org/10.3928/23258160-20131105-08

64. Spaide RF (2007) Chorioretinal inflammatory disorders. In: Holz FG, SchmitzValckenberg S, Spaide RF, Bird AC (eds) Atlas of fundus autofluorescence imaging. Springer, Heidelberg, pp 207-239

65. Pereira F, Lima LH, de Azevedo AGB, Zett C, Farah ME, Belfort R Jr (2018) Swept-source OCT in patients with multiple evanescent white dot syndrome. J Ophthalmic Inflamm Infect 8(1):16. https://doi.org/10.1186/ s12348-018-0159 2.PMID:30317398;PMCID:PMC6186261

66. Yannuzzi NA, Swaminathan SS, Zheng F, Miller A, Gregori G, Davis JL, Rosenfeld PJ (2017) Swept-source OCT angiography shows sparing of the Choriocapillaris in multiple evanescent white dot syndrome. Ophthalmic Surg Lasers Imaging Retina 48(1):69-74. https://doi.org/10.3928/23258160-2 0161219-10 PMID: 28060397

67. Kinouchi R, Nishikawa N, Ishibazawa A, Yoshida A (2017) Vascular rarefaction at the choriocapillaris in acute posterior multifocal placoid pigment epitheliopathy viewed on OCT angiography. Int Ophthalmol 37(3):733-736. https://doi.org/10.1007/s10792-016-0308-2 Epub 2016 Jul 28. PMID: 27469195]

68. Khochtali S, Dridi T, Abroug N, Ksiaa I, Lupidi M, Khairallah M (2020) SweptSource Optical Coherence Tomography Angiography Shows Choriocapillaris Flow Reduction in Multiple Evanescent White Dot Syndrome. J Curr Ophthalmol 32(2):211-215. https://doi.org/10.4103/JOCO.JOCO_107_20 PMID: 32671309; PMCID: PMC7337020

69. Kanski JJ, Pavésio CE, Tuft SJ (2006) Eds Elsevier Mosby. Prim Inflamm Choriocapillaropathies Ocul Inflamm Dis:221-233

70. Cimino L, Mantovani A, Herbort CP. Primary inflammatory choriocapillaropathies. In : Pleyer U, Mondino B, editors. Essentials in ophthalmology: ueitis and immunological disorders. Berlin: Springer; 2004, pp209-31, https://doi.org/10.1007/3-540-26752-2_14

71. Lages V, Mantovani A, Papadia M, Herbort CP (2018) MEWDS is a true primary choriocapillaritis and basic mechanisms do not seem to differ from other choriocapillaritis entities. J Curr Ophthalmol 30:281-286. https://doi. org/10.1016/j.joco 2018.09.009. eCollection 2018 Dec

72. Kang HG, Kim TY, Kim M, Byeon SH, Kim SS, Koh HJ, Lee SC, Lee CS (2020) Expanding the clinical spectrum of multiple evanescent white dot syndrome with overlapping multifocal choroiditis. Ocul Immunol Inflamm 1: 1-9. https://doi.org/10.1080/09273948.2020.1795206

73. Dell'omo R, Wong R, Marino M, Konstantinopoulos K, Pavésio C (2010) Relationship between different fluorescein and indocyanine green angiography features in multiple evanescent white dot syndrome. Br J Ophthalmol 94(1):59-63. https://doi.org/10.1136/bjo.2009163550. Epub 2009 Aug 18

74. Pellegrini M, Veronese C, Bernabei F, Lupidi M, Cerquaglia A, Invernizzi A, Zicarelli F, Cimino L, Bolletta E, Vagge A, Ciardella AP (2021) Choroidal vascular changes in multiple evanescent white dot syndrome. Ocul Immunol Inflamm 2021. Ocul Immunol Inflamm 29(2):340-345. https://doi. org/10.1080/09273948.2019.1678650

75. Hashimoto Y, Saito W, Saito M, Hirooka K, Mori S, Noda K, Ishida S (2015) Decreased choroidal blood flow velocity in the pathogenesis of multiple vanescent white dot syndrome. Graefes Arch Clin Exp Ophthalmol 253(9): 1457-1464. https://doi.org/10.1007/s00417-014-2831-z

76. Hashimoto Y, Saito W, Hasegawa Y, Noda K, Ishida S (2019) Involvement of inner choroidal layer in choroidal thinning during regression of multiple evanescent white dot syndrome. J Ophthalmol 2019:6816925. https://doi. org/10.1155/2019/6816925.eCollection2019

77. Ng CC, Jumper JM, Cunningham ET Jr (2020) Multiple evanescent white dot syndrome following influenza immunization: a multimodal imaging study. Am J ophthalmol Case Rep 19:100845. https://doi.org/10.1016/j.ajoc.2020.1 00845.eCollection2020Sep

78. Branisteanu D, Bilha A (2015) Acute posterior multifocal placoid pigment epitheliopathy following influenza vaccination. Rom J Ophthalmol 59:52-58 
79. Azar G, Wolff B, Azam S, Mauget-Faÿsse M (2021) Acute syphilitic posterior placoid chorioretinopathy presenting as atypical multiple evanescent white dot syndrome. Eur J Ophthalmol 31(2):NP141-NP144. https://doi.org/10.11 77/1120672120957589. Epub 2020 Sep 2

80. Gass JD, Agarwal A, Scott IU (2002) Acute zonal occult outer retinopathy: a long-term follow-up study. Am J Ophthalmol 134(3):329-339. https://doi. org/10.1016/S0002-9394(02)01640-9

81. Herbort CP Jr, Arapi I, Papasavvas I, Mantovani A, Jeannin B (2021) Acute Zonal Occult Outer Retinopathy (AZOOR) Results from a Clinicopathological Mechanism Different from Choriocapillaritis Diseases: A Multimodal Imaging Analysis. Diagnostics (Basel) 11(7):1184. https://doi.org/10.3390/diagnostics11 071184 PMID: 34209956; PMCID: PMC8303680

82. Mantovani A, Giani A, Herbort CP Jr, Staurenghi G (2016) Interpretation of fundus autofluorescence changes in choriocapillaritis: a multimodality imaging study. Graefes Arch Clin Exp Ophthalmol 254(8):1473-1479. https:// doi.org/10.1007/s00417-015-3205-x. Epub 2015 Dec 3

83. Cimino L, Auer C, Herbort CP (2000) Sensitivity of indocyanine green angiography for the follow-up of active inflammatory choriocapillaropathies. Ocul Immunol Inflamm 8(4):275-283. https://doi.org/10.1076/ocii.8.4.275.64 62

84. Furino C, Boscia F, Cardascia N, Alessio G, Sborgia C (2009) Fundus autofluorescence and multiple evanescent white dot syndrome. Retina 29(1):60-63. https://doi.org/10.1097//AE.0b013e31818c5e04

85. Penha FM, Navjas EV, Aggio FB, Rodrigues EB, Farah ME (2011) Fundus autofluorescence in multiple evanescent white dot syndrome. Case Rep Ophthalmol Med 2011:807565-807563. https://doi.org/10.1155/2011/807565. Epub 2011 Sep 21

86. Hashimoto H, Kishi S (2015) Ultra-wide-field fundus autofliorescence in multiple evanescent white dt syndrome. Am J Ophthalmol 159(4):698-706. https://doi.org/10.1016/j.ajo.2015.01.015. Epub 2015 Jan 26

87. Arai R, Kimura I, Imamura Y, Shinoda K, Matsumoto CS, Seki K, Ishida M, Murakami A, Mizota A (2014) Photoreceptors inner and outer segment layer thickness in multiple evanescent white dot syndrome. Graefes Arch Clin Exp Ophthalmol 252(10):1645-1651. https://doi.org/10.1007/s00417-014-2747-7

88. Hua R, Chen K, Liu LM, Liu NN, Chen L, Teng WP (2012) Multi-modality imaging on multiple evanescent white dot syndrome - a Spectralis study. Int J Ophthalmol 5(5):644-647. https://doi.org/10.3980/j.issn.2222-3959.2012. 05.21

89. Bryan RG, Freund KB, Yannuzzi LA, Spaide RF, Huang SJ, Costa DL (2002) Multiple evanescent white dot syndrome in patients with multifocal choroiditis. Retina 22(3):317-322. https://doi.org/10.1097/00006982-2002 06000-00010

90. Schaal S, Schiff WM, Kaplan HJ, Tezel TH (2009) Simultaneous appearance of multiple evanescent white dot syndrome and multifocal choroiditis indicate a common causal relationship. Ocul Immunol Inflamm 17(5):325-327. 19831 564. https://doi.org/10.3109/09273940903043923

91. Borruat FX, Auer C, Piguet B (1995) Choroidopathy in multiple evanescent white dot syndrome. Arch Ophthalmol 113(12):1569-1570. https://doi.org/1 0.1001/archopht.1995.01100120101021

92. Essilfie J, Bacci T, Abdelhakim AH, Ramtohul P, Turchi F, Freund KB, Yannuzz LA (2021) Are there two forms of multiple evanescent white dot syndrome? Retina Publish Ahead of Print. https://doi.org/10.1097/IAE.00000000000032 88

93. Russell JF, Pichi F, Scott NL, Hartley MJ, Bell D, Agarwal A, Leong B, Holland GN, Freund KB, Sarraf D (2020) Masqueraders of multiple evanescent white dot syndrome (MEWDS). Int Ophthalmol 40(3):627-638. https://doi.org/10.1 007/s10792-019-01223-4 Epub 2019 Dec 2. PMID: 31792848

\section{Publisher's Note}

Springer Nature remains neutral with regard to jurisdictional claims in published maps and institutional affiliations. 